\title{
Purification and biochemical characterization of recombinant Persicaria minor $\beta$-sesquiphellandrene synthase
}

\author{
De-Sheng Ker ${ }^{1}$, Sze Lei Pang ${ }^{1}$, Noor Farhan Othman ${ }^{1}$, Sekar Kumaran ${ }^{1}$, Ee Fun Tan ${ }^{1}$, Thiba Krishnan ${ }^{2}$, \\ Kok Gan Chan $^{2}$, Roohaida Othman ${ }^{1,3}$, Maizom Hassan ${ }^{\text {Corresp., }}{ }^{1}$, Chyan Leong Ng ${ }^{\text {Corresp. } 1}$ \\ 1 Institute of Systems Biology, Universiti Kebangsaan Malaysia, Bangi, Selangor, Malaysia \\ 2 Division of Genetics and Molecular Biology, Institute of Biological Sciences, Faculty of Science, University of Malaya, Kuala Lumpur, Malaysia \\ ${ }^{3}$ School of Biosciences and Biotechnology, Faculty of Science and Technology, Universiti Kebangsaan Malaysia, Bangi, Selangor, Malaysia \\ Corresponding Authors: Maizom Hassan, Chyan Leong Ng \\ Email address: maizom@ukm.edu.my, clng@ukm.edu.my
}

Background. Sesquiterpenes are 15-carbon terpenes synthesized by sesquiterpene synthases using farnesyl diphosphate (FPP) as a substrate. Recently, a sesquiterpene synthase gene that encodes a 65 kDa protein was isolated from the aromatic plant Persicaria minor. Here, we report the expression, purification and characterization of recombinant $P$. minor sesquiterpene synthase protein (PmSTS). Insights into the catalytic active site were further provided by structural analysis guided by multiple sequence alignment.

Methods. The enzyme was purified in two steps using affinity and size exclusion chromatography. Enzyme assays were performed using the malachite green assay and enzymatic product was identified using gas chromatography-mass spectrometry (GC-MS) analysis. Sequence analysis of PmSTS was performed using multiple sequence alignment (MSA) against plant sesquiterpene synthase sequences. The homology model of PmSTS was generated using I-TASSER server.

Results. Our findings suggest that the recombinant PmSTS is mainly expressed as inclusion bodies and soluble aggregate in the $E$. coli protein expression system. However, addition of $15 \%(\mathrm{v} / \mathrm{v})$ glycerol to the protein purification buffer and removal of N-terminal 24 amino acids of PmSTS helped to produce homogenous recombinant protein. Enzyme assay showed that recombinant PmSTS is active and specific to the $\mathrm{C}_{15}$ substrate FPP. The optimal temperature and $\mathrm{pH}$ for the recombinant PmSTS are $30^{\circ} \mathrm{C}$ and $\mathrm{pH}$ 8.0, respectively. The GC-MS analysis further showed that PmSTS produces $\beta$-sesquiphellandrene as a major product and $\beta$-farnesene as a minor product. MSA analysis revealed that PmSTS adopts a modified conserved metal binding motif (NSE/DTE motif). Structural analysis suggests that PmSTS may binds to its substrate similarly to other plant sesquiterpene synthases.

Discussion. The study has revealed that homogenous PmSTS protein can be obtained with the addition of glycerol in the protein buffer. The N-terminal truncation dramatically improved the homogeneity of PmSTS during protein purification, suggesting that the disordered $\mathrm{N}$-terminal region may have caused the formation of soluble aggregate. We further show that the removal of the N-terminus disordered region of PmSTS does not affect the product specificity. The optimal temperature, optimal $\mathrm{pH}, K_{\mathrm{m}}$ and $k_{\mathrm{cat}}$ values of PmSTS suggests that PmSTS shares similar enzyme characteristics with other plant sesquiterpene synthases. The discovery of an altered conserved metal binding motif in PmSTS through MSA analysis shows that the NSE/DTE motif commonly found in terpene synthases is able to accommodate certain level of plasticity to accept variant amino acids. Finally, the homology structure of PmSTS that allows good fitting of substrate analog into the catalytic active site suggests that PmSTS may adopt a sesquiterpene biosynthesis mechanism similar to other plant sesquiterpene synthases. 
1 Purification and biochemical characterization of recombinant Persicaria minor $\beta$ 2 sesquiphellandrene synthase

4 De-Sheng Ker ${ }^{1}$, Sze Lei Pang ${ }^{1}$, Noor Farhan Othman ${ }^{2}$, Sekar Kumaran ${ }^{1}$, Ee Fun Tan ${ }^{1}$, Thiba

5 Krishnan ${ }^{2}$, Kok Gan Chan ${ }^{2}$, Roohaida Othman ${ }^{1,3}$, Maizom Hassan ${ }^{1}$, Chyan Leong Ng ${ }^{*}$

$6{ }^{1}$ Institute of Systems Biology, Universiti Kebangsaan Malaysia, Bangi, Selangor, Malaysia

72 Division of Genetics and Molecular Biology, Institute of Biological Sciences, Faculty of

8 Science, University of Malaya, Kuala Lumpur, Malaysia

$9{ }^{3}$ School of Biosciences and Biotechnology, Faculty of Science and Technology, Universiti

10 Kebangsaan Malaysia, Bangi, Selangor, Malaysia

11 Corresponding authors:

Chyan Leong $\mathrm{Ng}^{1}$

Institute of Systems Biology, Universiti Kebangsaan Malaysia, Bangi, Selangor, Malaysia Email address: clng@ukm.edu.my

Maizom Hassan ${ }^{1}$

Institute of Systems Biology, Universiti Kebangsaan Malaysia, Bangi, Selangor, Malaysia Email address: maizom@ukm.edu.my

Abstract

Background. Sesquiterpenes are 15-carbon terpenes synthesized by sesquiterpene synthases using farnesyl diphosphate (FPP) as a substrate. Recently, a sesquiterpene synthase gene that encodes a $65 \mathrm{kDa}$ protein was isolated from the aromatic plant Persicaria minor. Here, we report the expression, purification and characterization of recombinant $P$. minor sesquiterpene synthase protein (PmSTS). Insights into the catalytic active site were further provided by structural analysis guided by multiple sequence alignment.

Methods. The enzyme was purified in two steps using affinity and size exclusion chromatography. Enzyme assays were performed using the malachite green assay and enzymatic product was identified using gas chromatography-mass spectrometry (GC-MS) analysis. Sequence analysis of PmSTS was performed using multiple sequence alignment (MSA) against plant sesquiterpene synthase sequences. The homology model of PmSTS was generated using ITASSER server. 
32 Results. Our findings suggest that the recombinant PmSTS is mainly expressed as inclusion bodies and soluble aggregate in the E. coli protein expression system. However, addition of $15 \%$ (v/v) glycerol to the protein purification buffer and removal of N-terminal 24 amino acids of PmSTS helped to produce homogenous recombinant protein. Enzyme assay showed that recombinant PmSTS is active and specific to the $\mathrm{C}_{15}$ substrate FPP. The optimal temperature and $\mathrm{pH}$ for the recombinant PmSTS are $30^{\circ} \mathrm{C}$ and $\mathrm{pH} 8.0$, respectively. The GC-MS analysis further showed that PmSTS produces $\beta$-sesquiphellandrene as a major product and $\beta$-farnesene as a minor product. MSA analysis revealed that PmSTS adopts a modified conserved metal binding motif (NSE/DTE motif). Structural analysis suggests that PmSTS may binds to its substrate similarly to other plant sesquiterpene synthases.

Discussion. The study has revealed that homogenous PmSTS protein can be obtained with the addition of glycerol in the protein buffer. The N-terminal truncation dramatically improved the homogeneity of PmSTS during protein purification, suggesting that the disordered N-terminal region may have caused the formation of soluble aggregate. We further show that the removal of the N-terminus disordered region of PmSTS does not affect the product specificity. The optimal temperature, optimal $\mathrm{pH}, K_{\mathrm{m}}$ and $k_{\mathrm{cat}}$ values of PmSTS suggests that PmSTS shares similar enzyme characteristics with other plant sesquiterpene synthases. The discovery of an altered conserved metal binding motif in PmSTS through MSA analysis shows that the NSE/DTE motif commonly found in terpene synthases is able to accommodate certain level of plasticity to accept variant amino acids. Finally, the homology structure of PmSTS that allows good fitting of substrate analog into the catalytic active site suggests that PmSTS may adopt a sesquiterpene biosynthesis mechanism similar to other plant sesquiterpene synthases.

Abbreviations

$\beta$ ME, $\beta$-mercaptoethanol; FPP, farnesyl diphosphate; GPP, geranyl diphosphate; GGPP, geranylgeranyl diphosphate; GC-MS, Gas Chromatography-Mass Spectrometer; IPTG, isopropyl $\beta$-D-1-thiogalactopyranoside; LB, Luria-Bertani; MSA, multiple sequence alignment; PmSTS, Persicaria minor sesquiterpene synthase; SDS-PAGE, SDS-polyacrylamide gel electrophoresis; SEC, Size exclusion chromatography

\section{Introduction}

Sesquiterpenes are a diverse group of 15 carbon long, volatile hydrocarbons assembled from three isoprenoid units, and are commonly found in plants, insects and fungi. Despite having only 15 carbon atoms, sesquiterpenes can be found forming many different and stereochemically complex structures in nature (Degenhardt, Köllner \& Gershenzon, 2009). Utilizing farnesyl diphosphate (FPP), sesquiterpene synthases generate more than 200 different sesquiterpene hydrocarbon skeletons which serve as precursors for more than 7000 derivative molecules (Cane, 
1990; Misawa, 2011; Srivastava et al., 2015). The biosynthesis of sesquiterpenes is initiated by metal-dependent ionization of FPP, followed by a series of complex chemical mechanisms, involving isomerizations, cyclizations and rearrangements, catalyzed by sesquiterpene synthases, which then generate sesquiterpene products (Dickschat, 2011; Tantillo, 2011). Normally, each sesquiterpene synthase generates a single major sesquiterpene as its product; however, some sesquiterpene synthases are able to produce multiple different sesquiterpene products (Christianson, 2008; Degenhardt, Köllner \& Gershenzon, 2009). For example, $\gamma$-humulene synthase from grand fir (Abies grandis) can produce 52 different sesquiterpenes (Steele et al., 1998). Nevertheless, the roles of majority of sesquiterpene synthases in guiding the specific mechanism of carbocation rearrangement to generate precise sesquiterpene remain unclear (O’Brien et al., 2016).

Taking advantage of the available transcriptome and genome data, functional genomics efforts have led to the discovery and characterization of sesquiterpene synthase genes from many fragrant plants including sweet wormwood (Artemisia annua) (Chang et al., 2000), tobacco (Nicotiana tabacum) (Back, Yin \& Chappell, 1994), lavender (Lavandula angustifolia) (Landmann et al., 2007; Jullien et al., 2014) and sandalwood (Santalum album) (Jones et al., 2011; Srivastava et al., 2015). Persicaria minor is an aromatic plant widely distributed in Southeast Asia. It possesses a wide range of biological activities and is used locally as remedies for digestive disorder and dandruff (Christapher et al., 2014; Vikram et al., 2014). Previous chemical studies of $P$. minor have shown that $P$. minor essential oil contains mainly aldehydes and terpenes (Baharum et al., 2010; Ahmad et al., 2014), and sesquiterpenes are found predominantly in the flower (Prota et al., 2014). A few enzymes involved in flavonoid and terpenoid metabolite biosynthesis including geraniol dehydrogenase, chalcone synthase, and farnesol dehydrogenase have been identified in P. minor (Hassan et al., 2012; Roslan et al., 2012; Ahmad Sohdi et al., 2015).

Recently, a putative $P$. minor sesquiterpene synthase (PmSTS) gene (GenBank: JX025008) has been isolated. The PmSTS gene encodes a 562 amino acid protein and belongs to the TPS-a subfamily of angiosperm sesquiterpene synthases (Ee et al., 2014). The PmSTS gene has been cloned and expressed in Escherichia coli (Tan \& Othman, 2012), gram positive bacteria Lactococcus lactic (Song et al., 2012) and in transgenic study of Arabidopsis thaliana (Ee et al., 2014). The His-tagged purified PmSTS from E. coli was found to produce $\alpha$-farnesene (Tan \& Othman, 2012), while His-tagged purified L. lactis recombinant PmSTS ${ }^{\mathrm{K} 266 \mathrm{E}}$ (containing a K266E mutation introduced during cloning process) was reported to catalyze the formation of $\beta$ sesquiphellandrene (Song et al., 2012). Moreover, metabolite profile analysis of transgenic $A$. thaliana also indicated that PmSTS may be responsible for the formation of $\beta$ sesquiphellandrene. Note that none of these studies have purified the enzyme to homogeneity for enzyme characterization and activity assay. To clarify if PmSTS is an $\alpha$-farnesene synthase or if the K266E mutation has changed the enzyme product to $\beta$-sesquiphellandrene, we conducted this work to purify the PmSTS to homogeneity for biochemical characterization. We report here the 
107

108

109

110

111

112

113

114

115

116

117

118

119

120

121

122

123

124

125

126

127

128

129

130

131

132

133

134

135

136

137

138

139

140

141

overexpression and purification of recombinant PmSTS protein in an E. coli system. The PmSTS was purified to homogeneity and used for enzyme characterization. The catalytic products were further analyzed using GC-MS. An homology model was utilized to provide insights into PmSTS active site in comparison with other sesquiterpene synthases.

\section{Material and Methods}

\section{Materials}

Pfu DNA polymerase was purchased from Biotechrabbit (Germany). Restriction enzymes and DNA ligase were purchased from Thermo Scientific (USA). DNA gel purification kits and plasmid purification kits were purchased from iNtRON Biotechnology (Korea). Farnesyl diphosphate (FPP), inorganic diphosphatase and standard alkane solution $\left(\mathrm{C}_{8}-\mathrm{C}_{20}\right)$ were obtained from Sigma-Aldrich (USA). Geranyl diphosphate (GPP) and geranylgeranyl diphosphate (GGPP) were purchased from Echelon Biosciences (USA). Malachite Green Phosphate Assay kit was obtained from Bioassay Systems (USA). QuikChange site-directed mutagenesis kit was obtained from Agilent Technologies (USA). HisTrap ${ }^{\mathrm{TM}}$ HP $5 \mathrm{~mL}$, and HiLoad 16/600 Superdex 200 pg were purchased from GE Healthcare (USA).

\section{Design of recombinant $P$. minor sesquiterpene synthase constructs (PmSTS- $\Delta 24)$}

To remove the N-terminal disordered region and enhance protein homogeneity, a truncated PmSTS construct, namely PmSTS__24 was generated from the full-length recombinant PmSTS using forward primer (5'-GCCCCTCGTCATATGGCAGGTTTCAAACCTTCC-3') and reverse primer (5'-CCAAGCTTTCATATCAGTATGGGATCGATGTAC-3'). The NdeI and HindIII restriction endonuclease sequences are underlined in these oligonucleotides, and the stop codon UGA is indicated in bold characters. The PCR amplification was performed according to the manufacturer's guidelines. The PCR product was analyzed by agarose gel electrophoresis and purified using DNA gel purification kit following manufacturer's guidelines. The purified PCR product was digested with $\mathrm{NdeI}$ and HindIII and ligated into pET28b expression vector.

\section{Molecular cloning}

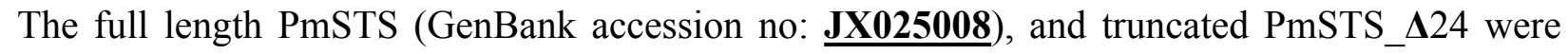
cloned into pET28b with the affinity tag $\left(\mathrm{His}_{6}\right)$ at its $\mathrm{N}$-terminus, which yielded the resulting

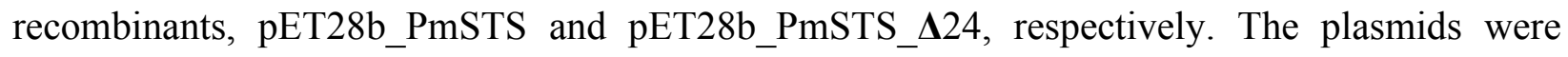
transformed into competent $E$. coli TOP 10 cells using heat shock at $42^{\circ} \mathrm{C}$ for $60 \mathrm{~s}$ and the transformants were selected on LB plates containing kanamycin $\left(50 \mu \mathrm{g} \mathrm{mL}^{-1}\right)$. Positive colonies were identified by colony PCR. Recombinant plasmid was isolated from positive transformants using a plasmid purification kit. The constructs were verified by Sanger DNA sequencing (First BASE Laboratories Sdn Bhd, Malaysia). 
142

143

144

145

146

147

148

149

150

151

152

153

154

155

156

157

158

159

160

161

162

163

164

165

166

167

168

169

170

171

172

173

174

175

176

177

178

\section{Protein expression of recombinant $P$. minor sesquiterpene synthase (PmSTS)}

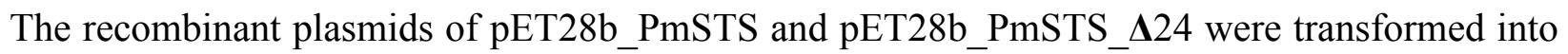
competent E. coli BL21 (DE3) cells. The effect of different temperature on the solubility of recombinant protein expression was investigated by isopropyl $\beta$-D-1-thiogalactopyranoside (IPTG) induction at $37^{\circ} \mathrm{C}$ and $16^{\circ} \mathrm{C}$. Briefly, a single colony was picked and cultured overnight at $37^{\circ} \mathrm{C}$ in $10 \mathrm{~mL}$ of sterile LB culture $\left(50 \mu \mathrm{g} \mathrm{mL}-1\right.$ of kanamycin) with agitation $200 \mathrm{rev} \mathrm{min}^{-1}$. The cells were allowed to grow at $37^{\circ} \mathrm{C}$ until $\mathrm{OD}_{600}$ reached 0.6 . The cultures grown at $37^{\circ} \mathrm{C}$ and $16^{\circ} \mathrm{C}$ were induced by adding IPTG to a final concentration of $0.5 \mathrm{mM}$. The culture was further incubated at $37^{\circ} \mathrm{C}$ and $16^{\circ} \mathrm{C}$ for 4 hours and 16 hours at $200 \mathrm{rev} \mathrm{min}{ }^{-1}$ respectively. Cells were harvested by centrifugation for $10 \mathrm{~min}$ at $5500 \mathrm{~g}$ at $4^{\circ} \mathrm{C}$ and stored frozen at $-80^{\circ} \mathrm{C}$ until use.

Cells that had been induced at $37^{\circ} \mathrm{C}$ and $16^{\circ} \mathrm{C}$ were resuspended in lysis buffer containing 20 $\mathrm{mM}$ Tris- $\mathrm{HCl}(\mathrm{pH} 8.0), 500 \mathrm{mM} \mathrm{NaCl}, 20 \mathrm{mM} \beta$-mercaptoethanol ( $\beta \mathrm{ME})$, and lysed with $10 \mathrm{~min}$ sonication composed of $5 \mathrm{~s}$ pulse with $10 \mathrm{~s}$ rest at amplitude $30 \%$ power using ultrasonicator (QSONICA) on ice. Cell lysate was then centrifuged at $13,000 \mathrm{~g}$ for $30 \mathrm{~min}$ at $4^{\circ} \mathrm{C}$. The pellet and supernatant corresponding to insoluble and soluble proteins were analyzed using SDSPAGE.

\section{Purification of recombinant $P$. minor sesquiterpene synthase (PmSTS)}

For protein purification, cell pellets harvested from $2 \mathrm{~L}$ of LB culture were used. The cell pellet was resuspended in $30 \mathrm{~mL}$ of binding buffer $(20 \mathrm{mM}$ Tris- $\mathrm{HCl}, \mathrm{pH} 8.0,500 \mathrm{mM} \mathrm{NaCl}, 20 \mathrm{mM}$ $\beta \mathrm{ME}, 20 \mathrm{mM}$ imidazole). For purification in the presence of glycerol, binding buffer $\mathrm{G}(20 \mathrm{mM}$ Tris-HCl, pH 8.0, $500 \mathrm{mM} \mathrm{NaCl}, 20 \mathrm{mM} \beta \mathrm{ME}, 20 \mathrm{mM}$ imidazole, 15\% (v/v) glycerol) was used instead. The cell suspensions were disrupted with a 10 min sonication composed of $15 \mathrm{~s}$ pulse with $30 \mathrm{~s}$ rest at amplitude of $30 \%$ power using an ultrasonicator (QSONICA) on ice. Cell lysate was then centrifuged at $13,000 \mathrm{~g}$ for $30 \mathrm{~min}$ at $4^{\circ} \mathrm{C}$. The supernatant fraction was filtered through a syringe filter $\left(0.2 \mu \mathrm{m}\right.$ pore size) before being applied into a HisTrap ${ }^{\mathrm{TM}} \mathrm{HP} 5 \mathrm{~mL}$ (GE Healthcare), pre-equilibrated with binding buffer. After washing of HisTrap ${ }^{\mathrm{TM}}$ with 10 column volumes $(\mathrm{CV})$ of binding buffer, protein was eluted with elution buffer $(20 \mathrm{mM}$ Tris- $\mathrm{HCl}, \mathrm{pH}$ 8.0, $500 \mathrm{mM} \mathrm{NaCl}, 20 \mathrm{mM} \beta \mathrm{ME}, 500 \mathrm{mM}$ imidazole) in $2 \mathrm{~mL}$ fractions by $20 \mathrm{CV}$ in linear gradient. Eluted protein fractions were pooled and concentrated to $2 \mathrm{~mL}$ using Microsap Advanced Centrifugal Device (10 kDa MWCO, Pall) at $4^{\circ} \mathrm{C}$ and were further purified using HiLoad 16/600 Superdex 200pg (GE Healthcare) at a flow rate of $0.8 \mathrm{~mL} \mathrm{~min}^{-1}$. Eluted protein fractions were pooled and concentrated using a Microsap Advanced Centrifugal Device (10 kDA MWCO, Pall).

\section{Enzyme assay}

Enzyme assays were performed using Malachite Green Phosphate Assay Kits (BioAssay Systems) in 96-well flat bottom plates. After purification, protein concentrations were determined using the Bradford Assay (Amesco). Briefly, 0.1 $\mu \mathrm{M}$ of purified enzyme was 
179

180

181

182

183

184

185

186

187

188

189

190

191

192

193

194

195

196

197

198

199

200

201

202

203

204

205

206

207

208

209

210

211

212

213

equilibrated in reaction mixture containing $20 \mathrm{mM}$ HEPES, $\mathrm{pH} 8.0,10 \mathrm{mM} \mathrm{MgCl}, 100 \mathrm{mU}$ inorganic diphosphatase for $2 \mathrm{~min}$ at room temperature. Reactions $(240 \mu \mathrm{L})$ were started by the addition of FPP, GPP or GGPP, and allowed to proceed at $30^{\circ} \mathrm{C}$ for $5 \mathrm{~min}$. After incubation, 80 $\mu \mathrm{L}$ of reaction mixture were transferred to each well (96-well plate) and the enzyme reactions were quenched by addition of $20 \mu \mathrm{L}$ of malachite green solution. After 20 min of incubation, reactions were read at $655 \mathrm{~nm}$ using an iMark plate reader (Bio Rad). Negative controls were performed without the addition of purified enzyme. Monophosphate (Pi) and diphosphate (PPi) were generated according to the instructions of the manufacturer.

\section{Enzyme characterization}

The optimal temperature was determined in a series of temperatures ranging from $25^{\circ} \mathrm{C}$ to $55^{\circ} \mathrm{C}$ in $20 \mathrm{mM}$ HEPES buffer ( $\mathrm{pH} \mathrm{8.0).} \mathrm{The} \mathrm{optimal} \mathrm{pH}$ was determined at room temperature from $\mathrm{pH}$ 6.0 to $\mathrm{pH} 10.5$ using $20 \mathrm{mM}$ BIS-TRIS propane, and $20 \mathrm{mM}$ glycine $\mathrm{NaOH}$ buffer. Kinetic parameters were determined in assays with ten different substrate concentrations ( 2 to $30 \mu \mathrm{M})$ at pH 8.0 and $30^{\circ} \mathrm{C}$ using $0.1 \mu \mathrm{M}$ of purified enzyme. Apparent $K_{\mathrm{m}}, k_{\text {cat }}$ and $k_{\text {cat }} / K_{\mathrm{m}}$ values were obtained with GraphPad Prism 5 software.

\section{Product identification using Gas Chromatography Mass Spectrometry (GC-MS)}

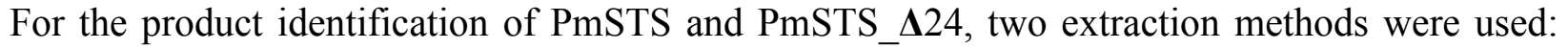
headspace solid phase microextraction (HS-SPME) and solvent extraction.

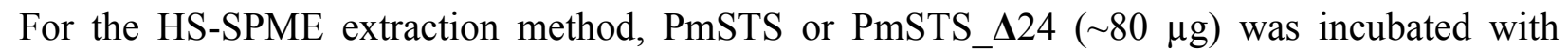
substrate $(60 \mu \mathrm{M}$ FPP) in assay buffer $(500 \mu \mathrm{L})$ containing $20 \mathrm{mM}$ HEPES (pH 8.0), $10 \mathrm{mM}$ $\mathrm{MgCl}_{2}$, and $1 \mathrm{mM}$ dithiothreitol. The reaction mixture was then incubated at $30^{\circ} \mathrm{C}$ for $2 \mathrm{~h}$, and the reaction products were extracted by HS-SPME using $100 \mu \mathrm{m}$ polydimethylsiloxane coated fiber (Supelco, USA). Headspace sampling times using SPME was $30 \mathrm{~min}$ at $45^{\circ} \mathrm{C}$ and the products were analyzed using GC-MS. GC-MS analysis was performed as described previously (Song et al., 2012; Tan, 2012) using Perkin Elmer, Turbomass Clarus 600 equipped with Perkin Elmer Elite $5 \mathrm{MS}$ (30 m length, I.D. $0.25 \mathrm{~mm}, 0.25 \mu \mathrm{m}$ film thickness).

For the solvent extraction method, the reaction mixtures were overlaid with $200 \mu \mathrm{L}$ of hexane to

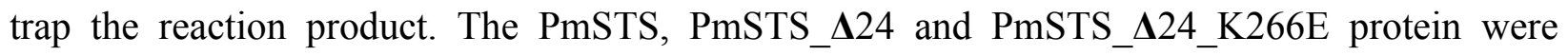
incubated overnight. After incubation, the hexane layer was extracted and subjected to GC-MS analysis. GC-MS analysis was performed as described previously (O’Maille, Chappell \& Noel, 2004) on an Agilent 7890A gas chromatograph equipped with HP-5MS (30 m length, I.D. 0.25 $\mathrm{mm}, 0.25 \mu \mathrm{m}$ film thickness) and 5975C MSD with triple-axis detector.

In both methods, products were identified based on their mass spectra and Kovats Index, calculated in relation to the retention times of a series of alkanes $\left(C_{8}\right.$ to $\left.C_{20}\right)$. The mass spectra 
214 were compared to those in the National Institute of Standards and Technology (NIST) library 2152011.

\section{Protein disordered region predictions}

217 The following servers were used for disordered region prediction of PmSTS: DISOPRED3 218 (Jones \& Cozzetto, 2015), DisEMBL (Linding et al., 2003), and RONN (Yang et al., 2005). In 219 all cases, PmSTS (residue 1 to 562) was subjected to disorder prediction using default server 220 parameters.

221

222

223

224

225

226

227

228

229

230

231

232

233

234

235

236

237

238

239

240

241

242

243

244

245

246

247

\section{Multiple sequence alignment and homology modelling}

Sequences of plant sesquiterpene synthase were obtained from the SWISS-PROT database through a text search for sesquiterpene. Protein sequences of 500 to 600 residues were retained and the proteins that produce sesquiterpene, as judged from available GC-MS analysis, were selected. Multiple sequence alignment (MSA) was performed using Clustal Omega webserver (Sievers et al., 2011). The alignment was then visualized and analyzed using Jalview 2 (Waterhouse et al., 2009). An homology model of PmSTS as previously reported (Ee et al., 2014) was constructed using I-Tasser (Roy, Kucukural \& Zhang, 2010). Superimposition of PmSTS with other terpene synthases (PDB: 3M01, 5EAT, 4FJQ, 3G4D, 1N20, 2ONG) were performed using Pymol (The PyMOL Molecular Graphics System, Version 1.8 Schrödinger, LLC.)

\section{Site-directed mutagenesis to generate PmSTS_ $\Delta 24^{\mathrm{K} 266 \mathrm{E}}$ mutant}

To generate the K266E mutant, site-directed mutagenesis was performed using QuikChange sitedirected mutagenesis kit (Agilent) according to the manufacturer's guidelines. The PCR-based mutagenesis protocol was performed with the PmSTS_A24 cDNAs cloned into the expression vector using forward primer GAAATGTGCAGGTGGTGGGAAAAGGTGAATATGACTAAG-3') and reverse primer (5'CTTAGTCATATTCACCTTTTCCCACCACCTGCACATTTC-3'). The mutagenized construct was fully sequenced before expression. The overexpression and purification of PmSTS_ $\Delta 24^{\mathrm{K} 266 \mathrm{E}}$ mutant protein was performed the same for the recombinant PmSTS.

\section{Results and discussion}

\section{Protein disordered region analysis of PmSTS lead to construct design of PmSTS_L24} protein

Analysis of PmSTS sequence using several disorder prediction servers suggested that the Nterminal region of PmSTS (about 1 to 25 amino acids residues) contains disordered regions (Figure S1). The disordered regions are amino acid regions that lack a stable secondary 
248

249

250

251

252

253

254

255

256

257

258

259

260

261

262

263

264

265

266

267

268

269

270

271

272

273

274

275

276

277

278

279

280

281

282

283

284

structures and have high conformational dynamics and flexibility that are susceptible to aggregation (Lebendiker \& Danieli, 2014). To eliminate the possibility of protein aggregation caused by the disordered region, and hence facilitate the purification of homogenous protein, the

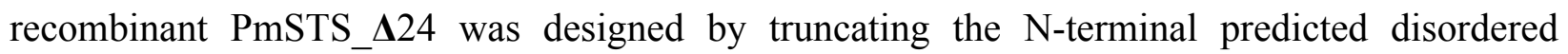
region.

\section{Cloning and over expression of recombinant $P$. minus sesquiterpene synthase (PmSTS)}

Full length recombinant sesquiterpene synthase of $P$. minor (PmSTS) and N-terminally truncated

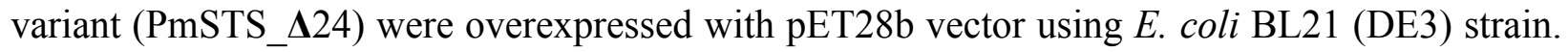
Both the PmSTS and the PmSTS_A24 recombinant proteins contain a His6-tag at its N-terminus to aid in the purification of recombinant protein using immobilized metal affinity chromatography (IMAC). To monitor the expression level and solubility properties of PmSTS

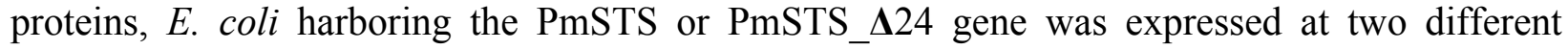
temperatures, $16^{\circ} \mathrm{C}$ and $37^{\circ} \mathrm{C}$. Recombinant cells grown at both $37^{\circ} \mathrm{C}$ and $16^{\circ} \mathrm{C}$ showed the production of recombinant enzyme, however soluble protein expressions of PmSTS and PmSTS_ $\Delta 24$ were only observed at $16^{\circ} \mathrm{C}$ (Figure 1). Expression at $37^{\circ} \mathrm{C}$ drove all the proteins into inclusion bodies (Figure 1). Lower growth temperature is known to facilitate the production of soluble recombinant protein through slowing down the transcription and translation rates, as well as reducing the strength of hydrophobic interactions that contribute to protein misfolding

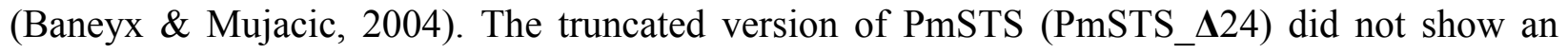
enhanced protein expression solubility despite the removal of the N-terminal disordered region (Figure 1B).

\section{Purification of recombinant PmSTS enzyme}

The recombinant protein purification was conducted using nickel affinity chromatography. The recombinant protein was eluted at $200 \mathrm{mM}$ imidazole, and the eluted protein fractions were identified by SDS-PAGE. The results showed high levels of E. coli contaminants eluted together with PmSTS (Figure 2A, lane 3). Additional protein purification using size exclusion chromatography (SEC) indicated that PmSTS may have bound together with the contaminants and formed soluble aggregates (Figure 2A). Further protein purification buffer optimization has identified that addition of $15 \%(\mathrm{v} / \mathrm{v})$ glycerol in protein purification buffer has aided in reducing the contaminants and improved the homogeneity of the PmSTS protein (Figure 2B), although the majority of the protein still remained as soluble aggregates. The SEC profile suggested that

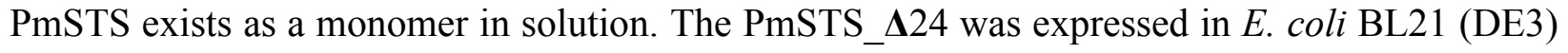
and purified using identical method as for PmSTS. The results revealed significant improvement in the purification profile of homogeneous PmSTS_\$24 compared to PmSTS (Figure 2C). Both systematic protein purification optimization and truncated protein design suggested that addition of glycerol in the buffer and elimination of N-terminus disordered region of PmSTS are important in producing homogenous PmSTS enzyme. 


\section{Enzyme characterization of PmSTS}

The purified full length PmSTS and PmSTS_\$24 proteins were used for biochemical characterization. Some sesquiterpene synthases have been reported to have broad substrate specificity, accepting both GPP and FPP as substrates (Nieuwenhuizen et al., 2009; Zhuang et al., 2012; Srivastava et al., 2015). However, the enzyme activity assay showed that both PmSTS

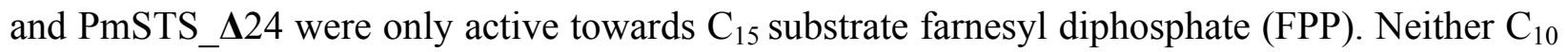
substrate geranyl diphosphate (GPP) nor $\mathrm{C}_{20}$ substrate geranylgeranyl diphosphate (GGPP) are

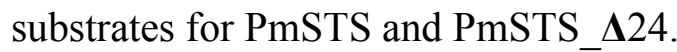

As for the determination of kinetic parameters, only the activity of PmSTS_ $\Delta 24$ was assayed. The purified full length PmSTS displayed enzyme instability and losing its activity over a period of time, thus making it unsuitable for the enzyme assay. The cause of the instability of PmSTS protein is yet to be investigated.

The optimal temperature for PmSTS_ $\Delta 24$ activity was found at $30^{\circ} \mathrm{C}$ (Figure $3 \mathrm{~A}$ ). At $40^{\circ} \mathrm{C}$, the enzymatic activity was less than $40 \%$ compared to that at $30^{\circ} \mathrm{C}$. The optimal $\mathrm{pH}$ range of the enzyme was further determined at $\mathrm{pH} 7.5$ to 8.0 (Figure $3 \mathrm{~B}$ ). The enzyme activity was found to

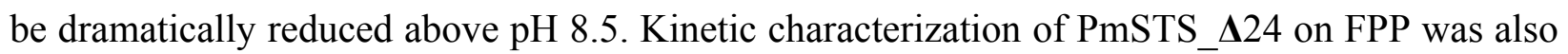
performed. PmSTS_ $\Delta 24$ has an apparent $K_{\mathrm{m}}$ value of $10.2 \mu \mathrm{M}$, a $k_{\text {cat }}$ value of $0.078 \mathrm{~s}^{-1}$ and $k_{\text {cat }} / K_{\mathrm{m}}$ of $7.6 \times 10^{3} \mathrm{M}^{-1} \mathrm{~s}^{-1}$. The optimal $\mathrm{pH}$ and temperature, as well as the kinetic parameters of PmSTS_\$24 are comparable to other plant sesquiterpene synthases (Table 1). As judged by the $k_{\text {cat }} / K_{\mathrm{m}}$ values, the plant sesquiterpene synthases, in general, have low catalytic activity. The low catalytic activity is common as the plant sesquiterpene synthases are plant enzymes involved in secondary metabolism, which are known to have $k_{\text {cat }} / K_{\mathrm{m}}$ values around $10^{3} \mathrm{M}^{-1} \mathrm{~s}^{-1}$ or lower (BarEven et al., 2011).

\section{$P$. minor sesquiterpene synthase produce $\beta$-sesquiphellandrene}

The enzyme assays of PmSTS and PmSTS_\$24 with FPP as substrate were performed by headspace solid phase microextraction gas chromatography mass spectrometry (HS-SPME-GCMS). The HS-SPME-GC-MS analysis of volatile sesquiterpene produced by PmSTS and

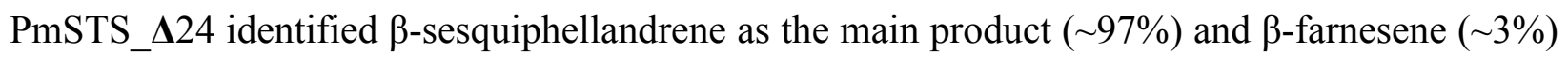
as a minor product (Figure 4). The HS-SPME result was further verified by solvent extraction using hexane, which showed that the major product is indeed $\beta$-sesquiphellandrene (KI:1516).

Previous GC-MS analysis of enzymatic reaction using partially purified recombinant PmSTS from E. coli showed that PmSTS produced $\alpha$-farnesene (Tan, 2012). However, further studies using partially purified recombinant PmSTS from L. lactis (Song et al., 2012) and metabolite studies of $A$. thaliana expressing PmSTS (Ee et al., 2014), have shown that PmSTS is a $\beta$ sesquiphellandrene synthase. In this study, the PmSTS that had been purified to homogeneity was further confirmed as a $\beta$-sesquiphellandrene synthase. In an effort to prove that the point mutation K266E, introduced during the cloning process in L. lactis (Song et al., 2012), does not 
322 interfere in product specificity of PmSTS, site-directed mutagenesis was undertaken to alter

323

324

325

326

327

328

329

330

331

332

333

334

335

336

337

338

339

340

341

342

343

344

345

346

347

348

349

350

351

352

353

354

355

356

357

residue lysine 266 to glutamic acid. The recombinant mutant protein K266E produced using an E. coli expression system displayed a product profile resembling that of PmSTS (Figure S5). Structural analysis revealed that residue K266E is located at the exterior surface of PmSTS (Figure 6C), and therefore is unlikely to affect the PmSTS product specificity. The truncated

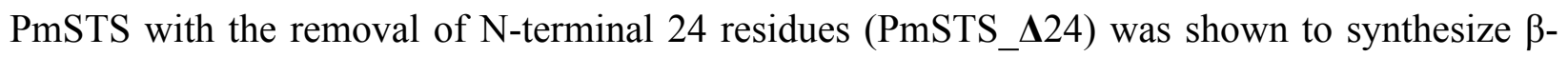
sesquiphellandrene as a major product, identical to the full length PmSTS. Thus, the N-terminal region is also not involved directly in product specificity of PmSTS, and similar properties have also been reported for truncated $\gamma$-humulene synthase from grand fir (Little \& Croteau, 2002).

$\beta$-Sesquiphellandrene is a sesquiterpene found as a constituent of ginger (Zingiber officinale) (Onyenekwe \& Hashimoto, 1999), turmeric (Curcuma longa) (Tyagi et al., 2015), and Alpinia conchigera (Ibrahim et al., 2009). Previous studies have shown that $\beta$ - sesquiphellandrene exhibits various biological activities such as antioxidant and anticancer activities (Zhao et al., 2010; Tyagi et al., 2015). Besides plants, $\beta$ - sesquiphellandrene has been found in insect as sex pheromone (Borges et al., 2007). In $P$. minor, sesquiphellandrene was detected at minute amount $(0.1 \%)$ in the leaves and stems (Ahmad et al., 2014).

Some plant sesquiterpene gene expressions have known to be mediated by plant developmental stages or environmental stresses (Bohlmann et al., 1998; Xu et al., 2004; Zhuang et al., 2012; Yu et al., 2015). For example, sesquiterpene synthases of rice (Os08g07100) and sorghum (SbTPS1, SbTPS2), that share $32 \%$ to $35 \%$ sequence identity with PmSTS, were found to produce $\beta$ sesquiphellandrene after damage by herbivores, suggesting that the emission of $\beta$ sesquiphellandrene play a role in crop defense (Yuan et al., 2008; Zhuang et al., 2012). The low abundance of sesquiphellandrene detected in $P$. minor may indicate similar regulation in the expression of sesquiterpene synthase (PmSTS).

\section{Multiple sequence alignment of plant sesquiterpene synthases and PmSTS reveals an altered second metal binding motif}

BLAST analysis revealed that PmSTS has high homology with sesquiterpene synthases of angiosperms, with the highest level of similarity (45\%) to drimenol synthase, a cyclic sesquiterpene synthase, from Persicaria hydropiper (GenBank Accession No: KC754968.1). PmSTS contains numerous motifs highly conserved among the plant sesquiterpene synthases, including RXR, DDXXD and NSE/DTE motifs (Ee et al., 2014). However, extensive MSA analysis in this study unexpectedly discovered that PmSTS contains a modified metal binding motif $\mathrm{N}^{458} \mathrm{DXXG}^{462} \mathrm{XXXV}^{466}$ on helix $\mathrm{H}$. This metal binding motif usually has consensus sequence (N/D)DXX(T/S/G)XXXE (Christianson, 2006; Zhou \& Peters, 2009) or DDXX(D/E) (Gennadios et al., 2009) in which boldface residues typically binds to one $\mathrm{Mg}$ cofactor, namely $\mathrm{Mg}^{2+} \mathrm{B}$. 
358

359

360

361

362

363

364

365

366

367

368

369

370

371

372

373

374

375

376

377

378

379

380

381

382

383

384

385

386

387

388

389

390

391

392

393

394

395

In PmSTS, the glutamate residue in metal binding motif (NDXXGXXXE) is found to be replaced by valine residue, $\mathrm{N}^{458} \mathrm{DXXG}^{462} \mathrm{XXXV}^{466}$, indicating that PmSTS contains a modified metal binding motif (Figure 5). This alternative form of motif has not been reported in plant sesquiterpene synthases. Previous mutational analyses on other terpene synthases have shown that changes from glutamate to glutamine or aspartate in the metal binding motif greatly reduce the catalytic activity and changes the product specificity of terpene synthases (Peters \& Croteau, 2002; Felicetti \& Cane, 2004). However, PmSTS was found to be fully active, despite the fact that the hydrophobic side chain of V466 is not able to form a hydrogen bond with a $\mathrm{Mg}^{2+}$ ion. It is likely that the side chain of N458 may still chelate the $\mathrm{Mg}^{2+}{ }_{\mathrm{B}}$ ion, with assistance from a water molecule (Zhou \& Peters, 2009) or carboxylic side chain of D459 (Figure S7), thereby PmSTS has a catalytic efficiency $\left(k_{\mathrm{cat}} / K_{\mathrm{m}}\right)$ that is comparable to other sesquiterpene synthases (Table 1$)$.

Multiple sequence alignment between linear and cyclic plant sesquiterpene synthase was performed to identify a potential conserved motif responsible for the cyclization in sesquiterpene synthases. However, MSA analysis did not find any motif that was able to distinguish between linear and cyclic sesquiterpene synthases. A similar result was obtained from phylogenetic analysis of various $\alpha$-farnesene synthases with other terpene synthases, as the phylogenetic analysis did not cluster all $\alpha$-farnesene synthase together in one group (Green et al., 2007). This is not surprising given the low sequence identity within sesquiterpene synthase family (Christianson, 2006; Aaron \& Christianson, 2010), even though most of the enzymes share a similar overall structure. Furthermore, based on current knowledge of sesquiterpene biosynthesis, it is still not possible to predict the absolute sesquiterpene product of a sesquiterpene synthase based on its amino acid sequence (Zulak \& Bohlmann, 2010; Dickschat, 2011).

\section{Homology model provides structural insights into PmSTS catalytic active site}

The previously generated homology model was used to gain structural insight into PmSTS catalytic mechanism (Ee et al., 2014). The overall structure of PmSTS adopts an $\alpha$-helical architecture containing two domains that resemble the terpene synthase family $\mathrm{N}$-terminal domain (residue 1 to 236 for PmSTS) and terpene synthase family C-terminal metal-binding domain (residue 237 to 562 for PmSTS), also known as a catalytic domain (Figure 6A). Based on the homology model, the predicted N-terminal 24 amino acid disordered region is positioned near the entrance of the active site; however, it does not affect the enzyme product specificity. Overall, the PmSTS structure is highly similar to other plant terpene synthases (Table 2). Despite lower sequence identity, PmSTS structure shared more similarity to the monoterpene synthase structure with lower RMSD than to its sesquiterpene synthase counterpart (Table 2). Structural comparison further revealed that the J-K loop and the second metal-binding motif region ( $\mathrm{H} 2$ helix and H2- $\alpha 1$ loop) are highly flexible compared to the conserved motif RXR and DDXXD located at helix D of the active site (Figure 6B). 
396

397

398

399

400

401

402

403

404

405

406

407

408

409

410

411

412

413

414

415

416

417

418

419

420

421

422

423

424

425

426

427

428

429

430

431

Superimposition of the PmSTS homology model to the substrate analog complex of Nicotiana tabacum 5-epi-aristolochene synthase (NtEAS; PDB:3M01) and Gossypium arboreum (+)-deltacadinene synthase (GaDCS; PDB:3G4F) showed that PmSTS may adopt a substrate binding like NtEAS (Figure 6B), but is unable to bind ligand as seen in GaDCS due to the ligand binding mode of GaDCS, which may cause steric clash with the J-K loop of PmSTS (Figure S8).

To better elucidate the function of $\beta$-sesquiphellandrene synthase, a structural study of PmSTS in complex with an FPP analog will be important to provide insights into the active site especially at the modified second metal-binding motif that is likely to interact with the $\mathrm{Mg}^{2+}{ }_{\mathrm{B}}$ ion.

Based on previous knowledge about the reaction mechanism of other sesquiterpene synthases (Köllner, Gershenzon \& Degenhardt, 2009; McAndrew et al., 2011; Garms et al., 2012), we proposed a reaction mechanism for PmSTS such that the biosynthesis of sesquiterpene begins with metal-dependent ionization of the diphosphate moiety of FPP to form a farnesyl cation and a diphosphate group (Figure 7). The diphosphate group will interact with and be stabilized by three $\mathrm{Mg}^{2+}$ ions and highly conserved positively charged residues, R277, R279, and R455. The positively charged region will direct the diphosphate away from the active site. Deprotonation of the farnesyl cation may yield the minor product $\beta$-farnesene. However, most of the farnesyl cation will undergo 1,6 cyclization via a nucleophilic attack of the $\mathrm{C} 6-\mathrm{C} 7$ double bond generating a bisabolyl cation. Subsequently, the 1,3-hydride shift between $\mathrm{C} 1$ and $\mathrm{C} 7$ and deprotonation at $\mathrm{C} 15$ will lead to the formation of $\beta$-sesquiphellandrene (Garms et al., 2012).

\section{Conclusion}

The sesquiterpene synthase gene from $P$. minor was successfully cloned, expressed and purified to homogeneity for the first time using an E. coli expression system. The truncation of the predicted unstructured N-terminal region of PmSTS dramatically increased the homogeneity of PmSTS, thus indicating that N-terminal disordered region may be one of the causes of PmSTS protein aggregation. The combination of $15 \%(\mathrm{v} / \mathrm{v})$ glycerol in protein purification buffer and elimination of the N-terminal disorder region of PmSTS are particularly important to produce homogenous PmSTS enzyme. These findings serve as an important example for the production of homogenous recombinant plant sesquiterpene synthases and may provide valuable information for future structural studies of PmSTS. GC-MS analysis revealed that both the full length PmSTS and truncated PmSTS_A24 recombinant proteins are active and produce mainly $\beta$-sesquiphellandrene.

Biochemical characterization of PmSTS showed that PmSTS utilizes FPP as a substrate and shares typical plant sesquiterpene synthases characteristics. No enzyme activity was detected when GPP or GGPP were used as substrate. Sequence alignment analysis identified a previously unreported altered conserved metal binding motif $\mathrm{N}^{458} \mathrm{DXXG}^{462} \mathrm{XXXV}^{466}$ in PmSTS, suggesting that sesquiterpene synthases are able to accommodate variant amino acid at this location. Finally, 
432 homology modelling and structural analyses suggest that PmSTS may likely bind to substrate in 433 a similar manner as to tobacco 5-epi-aristolochene synthase.

434

435

436

437

438

439

440

441

442

443

444

445

446

447

448

449

450

451

452

453

454

455

456

457

458

459

460

461

462

463

464

465

466

467

468

\section{Acknowledgement}

We thank Dr. Syarul Nataqain Baharum, Dr. Kamalrul Azlan Azizan, Syahmi Afiq Mustaza, Dr. Tan Cheng Seng, Dr. Teh Aik Hong, Dr. Lee Guan Serm, and Dr. Hong Sok Lai for the technical assistances and scientific discussion. We thank Dr. Paul Dear for reading and provides useful comments on the manuscript.

\section{References}

Aaron JA., Christianson DW. 2010. Trinuclear metal clusters in catalysis by terpenoid synthases. Pure and Applied Chemistry 82:1585-1597. DOI: 10.1351/PAC-CON-09-09-37.

Ahmad R., Baharum S., Bunawan H., Lee M., Noor N., Rohani E., Ilias N., Zin N. 2014. Volatile Profiling of Aromatic Traditional Medicinal Plant, Polygonum minus in Different Tissues and Its Biological Activities. Molecules 19:19220-19242. DOI: 10.3390/molecules 191119220.

Ahmad Sohdi NAS., Seman Kamarulzaman AF., Mohamed Hussein ZA., Hassan M. 2015. Purification and Characterization of a Novel NAD $(\mathrm{P})^{+}$-Farnesol Dehydrogenase from Polygonum minus Leaves. Plos One 10:e0143310. DOI: 10.1371/journal.pone.0143310.

Back K., Yin S., Chappell J. 1994. Expression of a plant sesquiterpene cyclase gene in Escherichia coli. Archives of Biochemistry and Biophysics 315:527-532.

Baharum SN., Bunawan H., Ghani MA., Mustapha WAW., Noor NM. 2010. Analysis of the chemical composition of the essential oil of Polygonum minus Huds. Using twodimensional gas chromatography-time-of-flight mass spectrometry (GC-TOF MS). Molecules 15:7006-7015. DOI: 10.3390/molecules15107006.

Baneyx F., Mujacic M. 2004. Recombinant protein folding and misfolding in Escherichia coli. Nature biotechnology 22:1399-1408. DOI: 10.1038/nbt1029.

Bar-Even A., Noor E., Savir Y., Liebermeister W., Davidi D., Tawfik DS., Milo R. 2011. The moderately efficient enzyme: Evolutionary and physicochemical trends shaping enzyme parameters. Biochemistry 50:4402-4410. DOI: 10.1021/bi2002289.

Bohlmann J., Crock J., Jetter R., Croteau R. 1998. Terpenoid-based defenses in conifers: cDNA cloning, characterization, and functional expression of wound-inducible (E)-alphabisabolene synthase from grand fir (Abies grandis). Proceedings of the National Academy of Sciences of the United States of America 95:6756-6761. DOI: 10.1073/pnas.95.12.6756.

Borges M., Millar JG., Laumann RA., Moraes MCB. 2007. A male-produced sex pheromone from the neotropical redbanded stink bug, Piezodorus guildinii (W.). Journal of Chemical Ecology 33:1235-1248. DOI: 10.1007/s10886-007-9294-1. 
469

470

471

472

473

474

475

476

477

478

479

480

481

482

483

484

485

486

487

488

489

490

491

492

493

494

495

496

497

498

499

500

501

502

503

504

505

Cai Y., Jia J-W., Crock J., Lin Z-X., Chen X-Y., Croteau R. 2002. A cDNA clone for betacaryophyllene synthase from Artemisia annua. Phytochemistry 61:523-529. DOI: S0031942202002650.

Cane DE. 1990. Enzymic formation of sesquiterpenes. Chemical Reviews 90:1089-1103. DOI: $10.1021 / \mathrm{cr} 00105 \mathrm{a} 002$.

Chang YJ., Song SH., Park SH., Kim SU. 2000. Amorpha-4,11-diene synthase of Artemisia anпua: cDNA isolation and bacterial expression of a terpene synthase involved in artemisinin biosynthesis. Archives of biochemistry and biophysics 383:178-84. DOI: 10.1006/abbi.2000.2061.

Christapher PV., Parasuraman S., Christina JMA., Asmawi MZ., Vikneswaran M. 2014. Review on Polygonum minus. Huds, a commonly used food additive in Southeast Asia. Pharmacognosy research 7:1-6. DOI: 10.4103/0974-8490.147125.

Christianson DW. 2006. Structural Biology and Chemistry of the Terpenoid Cyclases Structural Biology and Chemistry of the Terpenoid Cyclases. Chemical reviews 106:3412-3442. DOI: $10.1021 / \mathrm{cr} 050286 \mathrm{w}$.

Christianson DW. 2008. Unearthing the roots of the terpenome. Current Opinion in Chemical Biology 12:141-150. DOI: 10.1016/j.cbpa.2007.12.008.

Degenhardt J., Köllner TG., Gershenzon J. 2009. Monoterpene and sesquiterpene synthases and the origin of terpene skeletal diversity in plants. Phytochemistry 70:1621-1637. DOI: 10.1016/j.phytochem.2009.07.030.

Deguerry F., Pastore L., Wu S., Clark A., Chappell J., Schalk M. 2006. The diverse sesquiterpene profile of patchouli, Pogostemon cablin, is correlated with a limited number of sesquiterpene synthases. Archives of Biochemistry and Biophysics 454:123-136. DOI: 10.1016/j.abb.2006.08.006.

Dickschat JS. 2011. Isoprenoids in three-dimensional space: the stereochemistry of terpene biosynthesis. Natural Product Reports 28:1917. DOI: 10.1039/c1np00063b.

Ee SF., Mohamed Hussein ZA., Othman R., Shaharuddin NA., Ismail I., Zainal Z. 2014. Functional characterization of sesquiterpene synthase from Polygonum minus. TheScientificWorldJournal 2014:840592. DOI: 10.1155/2014/840592.

Felicetti B., Cane DE. 2004. Aristolochene synthase: Mechanistic analysis of active site residues by site-directed mutagenesis. Journal of the American Chemical Society 126:7212-7221. DOI: $10.1021 /$ ja0499593.

Garms S., Chen F., Boland W., Gershenzon J., Köllner TG. 2012. A single amino acid determines the site of deprotonation in the active center of sesquiterpene synthases SbTPS1 and SbTPS2 from Sorghum bicolor. Phytochemistry 75:6-13. DOI: 10.1016/j.phytochem.2011.12.009. 
506

Gennadios HA., Gonzalez V., Di Costanzo L., Li A., Yu F., Miller DJ., Allemann RK., Christianson DW. 2009. Crystal structure of (+)-delta-cadinene synthase from Gossypium arboreum and evolutionary divergence of metal binding motifs for catalysis. Biochemistry 48:6175-83. DOI: 10.1021/bi900483b.

Green S., Friel EN., Matich A., Beuning LL., Cooney JM., Rowan DD., MacRae E. 2007. Unusual features of a recombinant apple $\alpha$-farnesene synthase. Phytochemistry 68:176-188. DOI: $10.1016 /$ j.phytochem.2006.10.017.

Hassan M., Maarof ND., Ali ZM., Noor NM., Othman R., Mori N. 2012. Monoterpene Alcohol Metabolism: Identification, Purification, and Characterization of Two Geraniol Dehydrogenase Isoenzymes from Polygonum minus Leaves. Bioscience, Biotechnology and Biochemistry 76:1463-1470. DOI: 10.1271/bbb.120137.

Ibrahim H., Aziz AN., Syamsir DR., Ali NAM., Mohtar M., Ali RM., Awang K. 2009. Essential oils of Alpinia conchigera Griff. and their antimicrobial activities. Food Chemistry 113:575-577. DOI: 10.1016/j.foodchem.2008.08.033.

Jones CG., Moniodis J., Zulak KG., Scaffidi A., Plummer JA., Ghisalberti EL., Barbour EL., Bohlmann J. 2011. Sandalwood Fragrance Biosynthesis Involves Sesquiterpene Synthases of Both the Terpene Synthase (TPS)-a and TPS-b Subfamilies, including Santalene Synthases. Journal of Biological Chemistry 286:17445-17454. DOI: 10.1074/jbc.M111.231787.

Jones DT., Cozzetto D. 2015. DISOPRED3: precise disordered region predictions with annotated protein-binding activity. Bioinformatics 31:857-863. DOI: 10.1093/bioinformatics/btu744.

Jullien F., Moja S., Bony A., Legrand S., Petit C., Benabdelkader T., Poirot K., Fiorucci S., Guitton Y., Nicolè F., Baudino S., Magnard JL. 2014. Isolation and functional characterization of a $\tau$-cadinol synthase, a new sesquiterpene synthase from Lavandula angustifolia. Plant Molecular Biology 84:227-241. DOI: 10.1007/s11103-013-0131-3.

Köllner TG., Gershenzon J., Degenhardt J. 2009. Molecular and biochemical evolution of maize terpene synthase 10, an enzyme of indirect defense. Phytochemistry 70:1139-1145. DOI: 10.1016/j.phytochem.2009.06.011.

Landmann C., Fink B., Festner M., Dregus M., Engel KH., Schwab W. 2007. Cloning and functional characterization of three terpene synthases from lavender (Lavandula angustifolia). Archives of Biochemistry and Biophysics 465:417-429. DOI: 10.1016/j.abb.2007.06.011.

Lebendiker M., Danieli T. 2014. Production of prone-to-aggregate proteins. FEBS Letters 588:236-246. DOI: 10.1016/j.febslet.2013.10.044.

Linding R., Jensen LJ., Diella F., Bork P., Gibson TJ., Russell RB. 2003. Protein disorder prediction: Implications for structural proteomics. Structure 11:1453-1459. DOI: 10.1016/j.str.2003.10.002.

Little DB., Croteau RB. 2002. Alteration of product formation by directed mutagenesis and 
544

562

563

564

565

566

567

568

569

570

571

572

573

574

575

576

577

578

579

580

581

582

truncation of the multiple-product sesquiterpene synthases $\delta$-selinene synthase and $\gamma$ humulene synthase. Archives of Biochemistry and Biophysics 402:120-135. DOI: 10.1016/S0003-9861(02)00068-1.

McAndrew RP., Peralta-Yahya PP., Degiovanni A., Pereira JH., Hadi MZ., Keasling JD., Adams PD. 2011. Structure of a three-domain sesquiterpene synthase: A prospective target for advanced biofuels production. Structure 19:1876-1884. DOI: 10.1016/j.str.2011.09.013.

Misawa, N. (2011). Pathway engineering for functional isoprenoids. Current Opinion in Biotechnology, 22(5), 627-633. http://doi.org/10.1016/j.copbio.2011.01.002

Nieuwenhuizen NJ., Wang MY., Matich AJ., Green S a., Chen X., Yauk YK., Beuning LL., Nagegowda D a., Dudareva N., Atkinson RG. 2009. Two terpene synthases are responsible for the major sesquiterpenes emitted from the flowers of kiwifruit (Actinidia deliciosa). Journal of Experimental Botany 60:3203-3219. DOI: 10.1093/jxb/erp162.

O’Brien T., Bertolani SJ., Tantillo DJ., Siegel JB. 2016. Mechanistically informed predictions of binding modes for carbocation intermediates of a sesquiterpene synthase reaction. Chem. Sci.:1-7. DOI: 10.1039/C6SC00635C.

O’Maille PE., Chappell J., Noel JP. 2004. A single-vial analytical and quantitative gas chromatography-mass spectrometry assay for terpene synthases. Analytical Biochemistry 335:210-217. DOI: 10.1016/j.ab.2004.09.011.

Onyenekwe PC., Hashimoto S. 1999. The composition of the essential oil of dried Nigerian ginger (Zingiber officinale Roscoe). European Food Research and Technology 209:407410. DOI: $10.1007 / \mathrm{s} 002170050517$.

Peters RJ., Croteau RB. 2002. Abietadiene synthase catalysis: mutational analysis of a prenyl diphosphate ionization-initiated cyclization and rearrangement. Proceedings of the National Academy of Sciences of the United States of America 99:580-584. DOI: 10.1073/pnas.022627099.

Picaud S., Brodelius M., Brodelius PE. 2005. Expression, purification and characterization of recombinant (E)- $\beta$-farnesene synthase from Artemisia annua. Phytochemistry 66:961-967. DOI: $10.1016 /$ j.phytochem.2005.03.027.

Prota N., Mumm R., Bouwmeester HJ., Jongsma MA. 2014. Comparison of the chemical composition of three species of smartweed (genus Persicaria) with a focus on drimane sesquiterpenoids. Phytochemistry 108:129-136. DOI: 10.1016/j.phytochem.2014.10.001.

Roslan ND., Yusop JM., Baharum SN., Othman R., Mohamed Hussein ZA., Ismail I., Noor NM., Zainal Z. 2012. Flavonoid Biosynthesis Genes Putatively Identified in the Aromatic Plant Polygonum minus via Expressed Sequences Tag (EST) Analysis. International Journal of Molecular Sciences 13:2692-2706. DOI: 10.3390/ijms13032692.

Roy A., Kucukural A., Zhang Y. 2010. I-TASSER : a unified platform for automated protein structure and function prediction. Nature Protocols 5:725-738. DOI: 10.1038/nprot.2010.5.Sievers F., Wilm A., Dineen D., Gibson TJ., Karplus K., Li W., Lopez R., McWilliam H., Remmert M., Söding J., Thompson JD., Higgins DG. 2011. Fast, 
589

590

591

592

593

594

595

596

597

598

599

600

601

602

603

604

605

606

607

608

609

610

611

612

613

614

615

616

617

618

619

620

scalable generation of high-quality protein multiple sequence alignments using Clustal Omega. Molecular systems biology 7:539. DOI: 10.1038/msb.2011.75.

Song AAL., Abdullah JO., Abdullah MP., Shafee N., Othman R., Tan EF., Noor NM., Raha AR. 2012. Overexpressing 3-Hydroxy-3-Methylglutaryl Coenzyme A Reductase (HMGR) in the Lactococcal Mevalonate Pathway for Heterologous Plant Sesquiterpene Production. PLoS ONE 7:1-10. DOI: 10.1371/journal.pone.0052444.

Srivastava PL., Daramwar PP., Krithika R., Pandreka A., Shankar SS., Thulasiram H V. 2015. Functional Characterization of Novel Sesquiterpene Synthases from Indian Sandalwood, Santalum album. Scientific Reports 5:12. DOI: 10.1038/srep10095.

Steele CL., Crock J., Bohlmann J., Croteau R. 1998. Sesquiterpene Synthases from Grand Fir (Abies grandis). The Journal of Biological Chemistry 273:2078-2089. DOI: 10.1074/jbc.273.4.2078.

Tan EF., Othman R. 2012. Characterization of $\alpha$-Farnesene Synthase Gene from Polygonum minus. Transactions of The Malaysian Society of Plant Physiology 20:155-157. ISBN: 978967-10840-1-4.

Tyagi AK., Prasad S., Yuan W., Li S., Aggarwal BB. 2015. Identification of a novel compound ( $\beta$-sesquiphellandrene) from turmeric (Curcuma longa) with anticancer potential: Comparison with curcumin. Investigational New Drugs 33:1175-1186. DOI: 10.1007/s10637-015-0296-5.

Vikram P., Chiruvella KK., Ripain IHA., Arifullah M. 2014. A recent review on phytochemical constituents and medicinal properties of kesum (Polygonum minus Huds.). Asian Pacific Journal of Tropical Biomedicine 4:430-435. DOI: 10.12980/APJTB.4.2014C1255.

Waterhouse AM., Procter JB., Martin DMA., Clamp M., Barton GJ. 2009. Jalview Version 2-A multiple sequence alignment editor and analysis workbench. Bioinformatics 25:1189-1191. DOI: 10.1093/bioinformatics/btp033.

Xu YH., Wang JW., Wang S., Wang JY., Chen XY. 2004. Characterization of GaWRKY1, a cotton transcription factor that regulates the sesquiterpene synthase gene (+)-delta-cadinene synthase-A. Plant physiology 135:507-15. DOI: 10.1104/pp.104.038612.

Yang ZR., Thomson R., McNeil P., Esnouf RM. 2005. RONN: The bio-basis function neural network technique applied to the detection of natively disordered regions in proteins. Bioinformatics 21:3369-3376. DOI: 10.1093/bioinformatics/bti534.

Yu Z., Wang L., Zhao B., Shan C., Zhang Y., Chen D., Chen X. 2015. Progressive Regulation of Sesquiterpene Biosynthesis in Arabidopsis and Patchouli (Pogostemon cablin) by the miR156-Targeted SPL Transcription Factors. Molecular Plant 8:98-110. DOI: 10.1016/j.molp.2014.11.002.

Yuan JS., Ko TG., Wiggins G., Grant J. 2008. Molecular and genomic basis of volatile-mediated indirect defense against insects in rice. The Plant Journal 55:491-503. DOI: 10.1111/j.1365-313X.2008.03524.x. 
621 Zhao J., Zhang JS., Yang B., Lv GP., Li SP. 2010. Free radical scavenging activity and

622

623

624

625

626

627

628

629

630

631

632

633

634

635

636 characterization of sesquiterpenoids in four species of curcuma using a TLC bioautography assay and GC-MS analysis. Molecules 15:7547-7557. DOI: 10.3390/molecules15117547.

Zhou K., Peters RJ. 2009. Investigating the conservation pattern of a putative second terpene synthase divalent metal binding motif in plants. Phytochemistry 70:366-369. DOI: 10.1016/j.phytochem.2008.12.022.

Zhuang X., Köllner TG., Zhao N., Li G., Jiang Y., Zhu L., Ma J., Degenhardt J., Chen F. 2012. Dynamic evolution of herbivore-induced sesquiterpene biosynthesis in sorghum and related grass crops. The Plant Journal 69:70-80. DOI: 10.1111/j.1365-313X.2011.04771.x.

Zulak KG., Bohlmann J. 2010. Terpenoid biosynthesis and specialized vascular cells of conifer defense. Journal of Integrative Plant Biology 52:86-97. DOI: 10.1111/j.17447909.2010.00910.x.

(1) 


\section{Figure 1}

Expression analysis of (A) recombinant PmSTS and (B) truncated recombinant PmSTS_L24 from E. coli BL21 (DE3).

Soluble protein expression of PmSTS and PmSTS_ $\Delta 24$ were only observed at growth temperature $16^{\circ} \mathrm{C} . \mathrm{M}$ : protein marker (kDa). 1: Uninduced sample. 2: Sample induced with $0.5 \mathrm{mM}$ IPTG at $37^{\circ} \mathrm{C}$. 3: Sample induced with $0.5 \mathrm{mM}$ IPTG at $16^{\circ} \mathrm{C}$. 
A

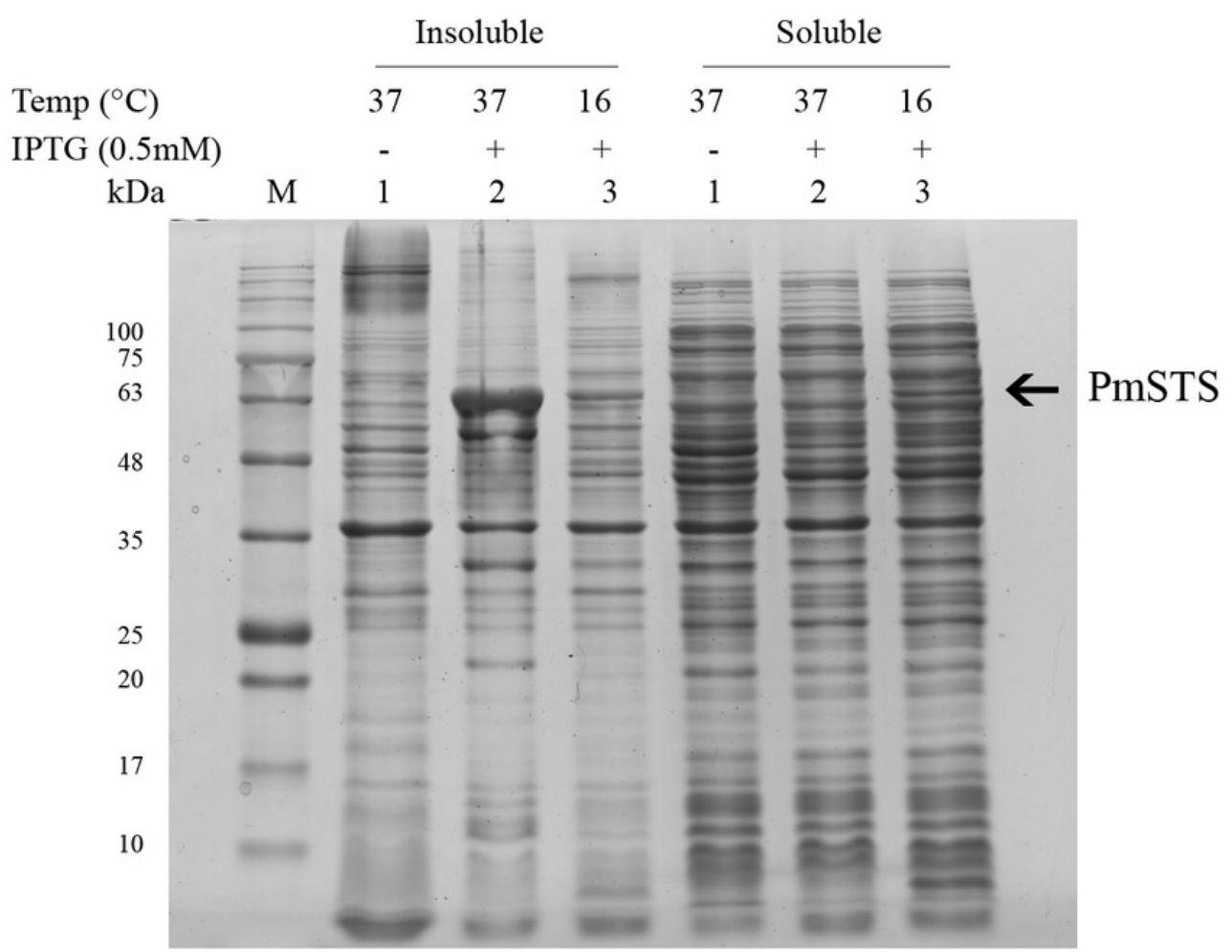

B

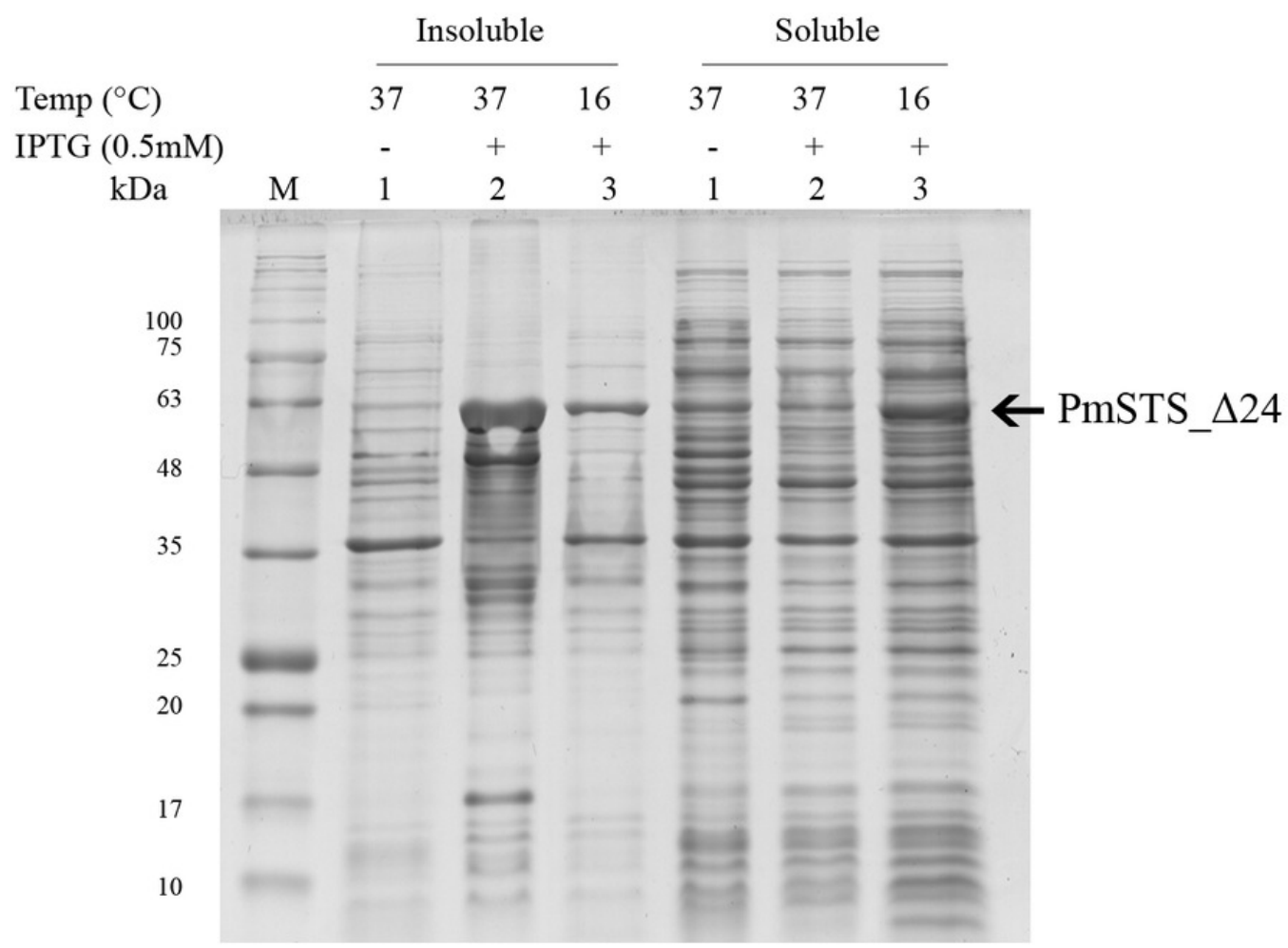




\section{Figure 2}

Size exclusion chromatography (SEC) and SDS-PAGE profile of PmSTS.

(A) SEC and SDS PAGE profile of PmSTS without presence of glycerol in the purification buffer. (B) SEC and SDS PAGE profile of PmSTS in the presence of 15\% (v/v) glycerol in the purification buffer. (C) SEC and SDS PAGE profile of truncated PmSTS_ $\triangle 24$ in the presence of $15 \%(\mathrm{v} / \mathrm{v})$ glycerol in the purification buffer. M: protein molecular weight markers (kDa), 1: Soluble fraction of uninduced cell lysate, 2: Soluble fraction of induced cell lysate, 3: Protein purified by immobilized metal affinity chromatography (IMAC), 4: Protein fraction from peak 4 in SEC, 5: Protein fraction from peak 5 in SEC. 
A

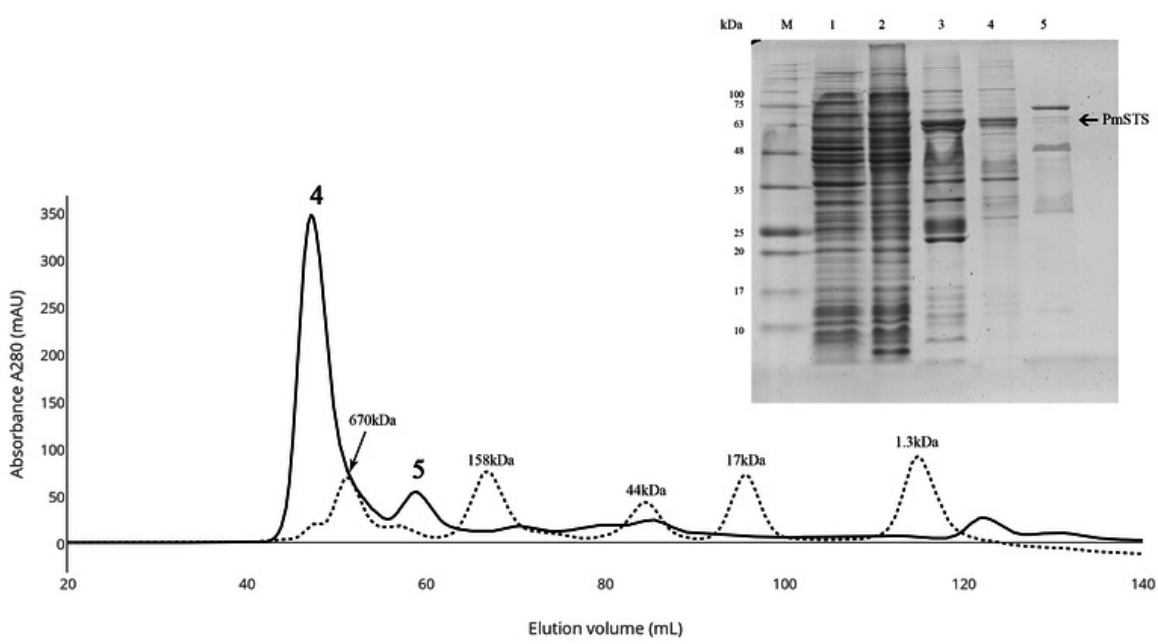

B
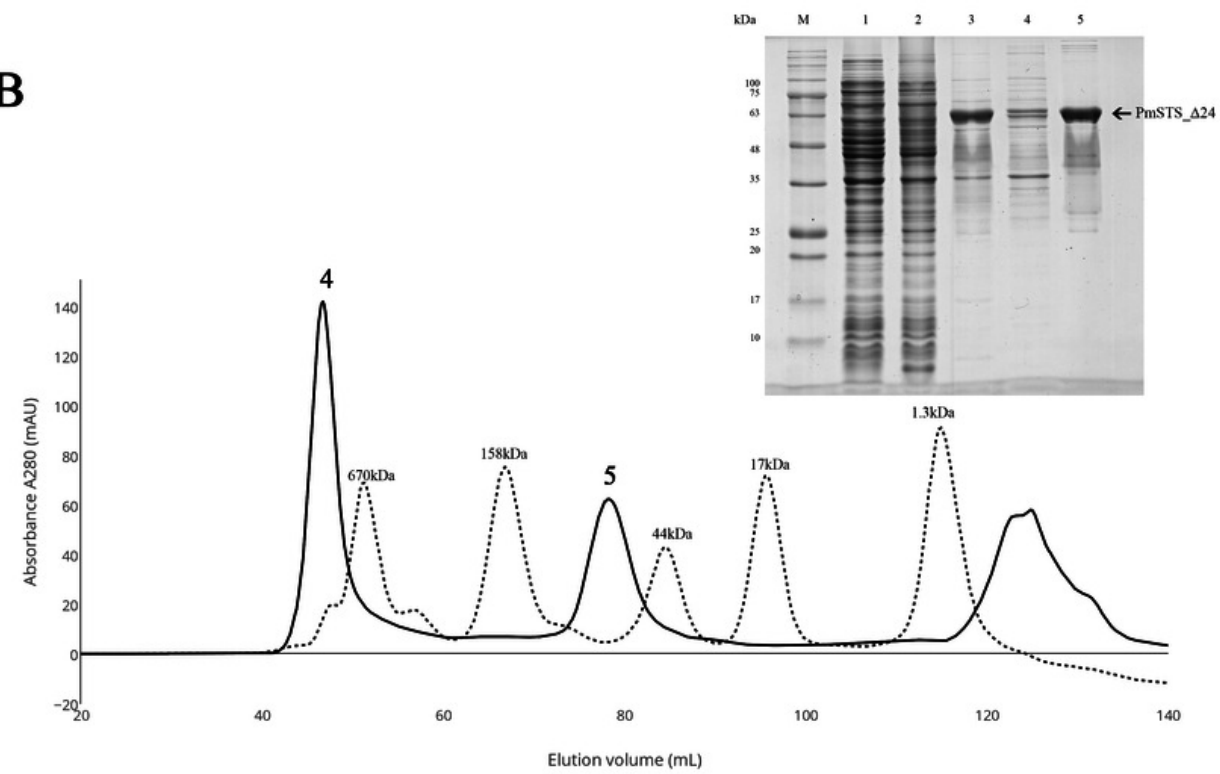

C

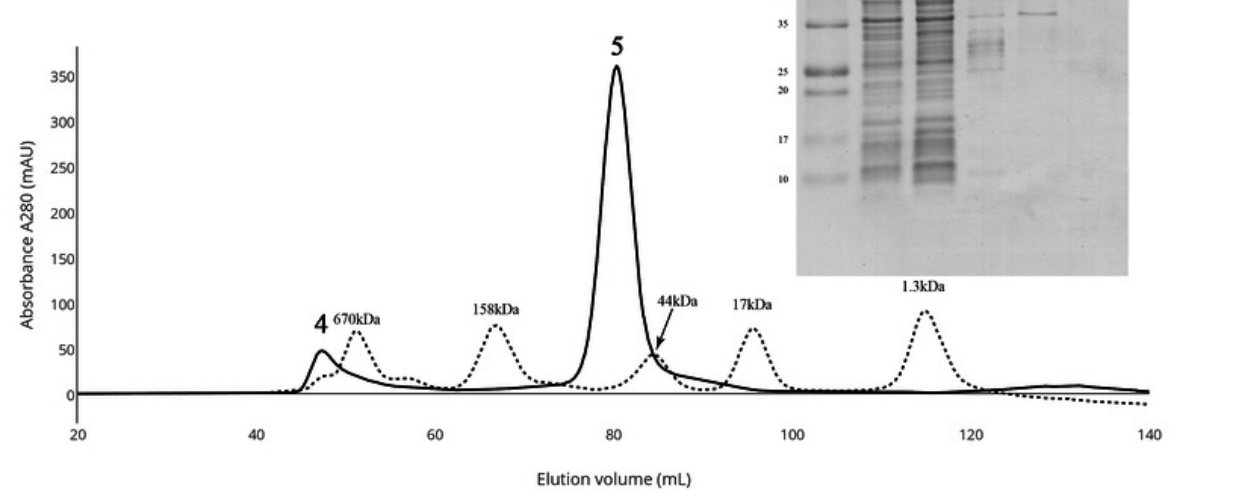




\section{Figure 3}

Biochemical analysis of PmSTS_ $\Delta 24$.

The purified PmSTS_ $\Delta 24$ was incubated with farnesyl diphosphate (FPP) at (A) different temperature and (B) different pH. (C) Michaelis-Menten plot for PmSTS_ $\Delta 24$. Error bars denote standard deviation $(n=3)$. Error bars denote standard deviation $(n=3)$. 
A

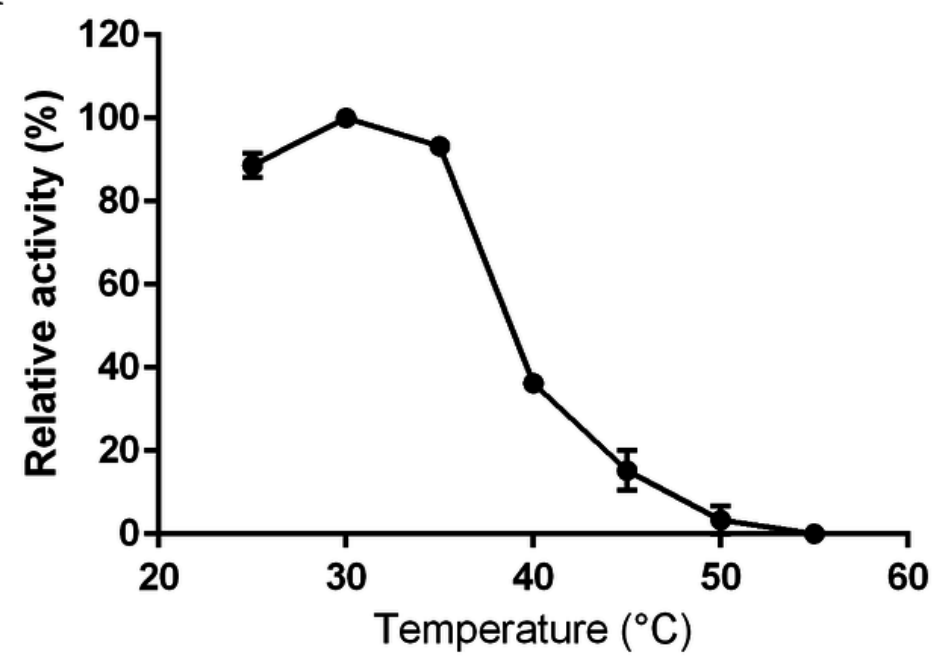

B

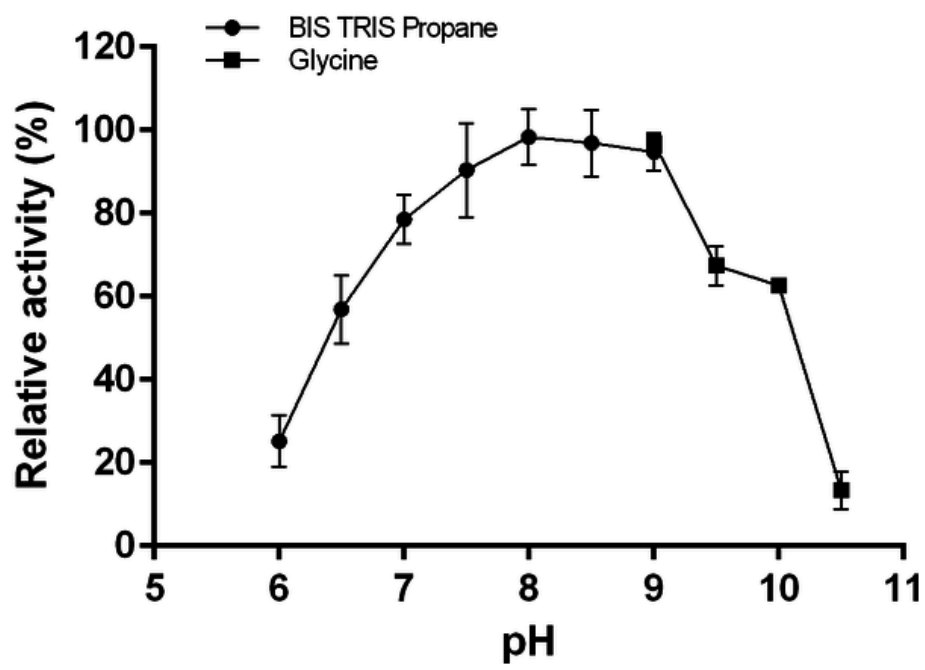

C

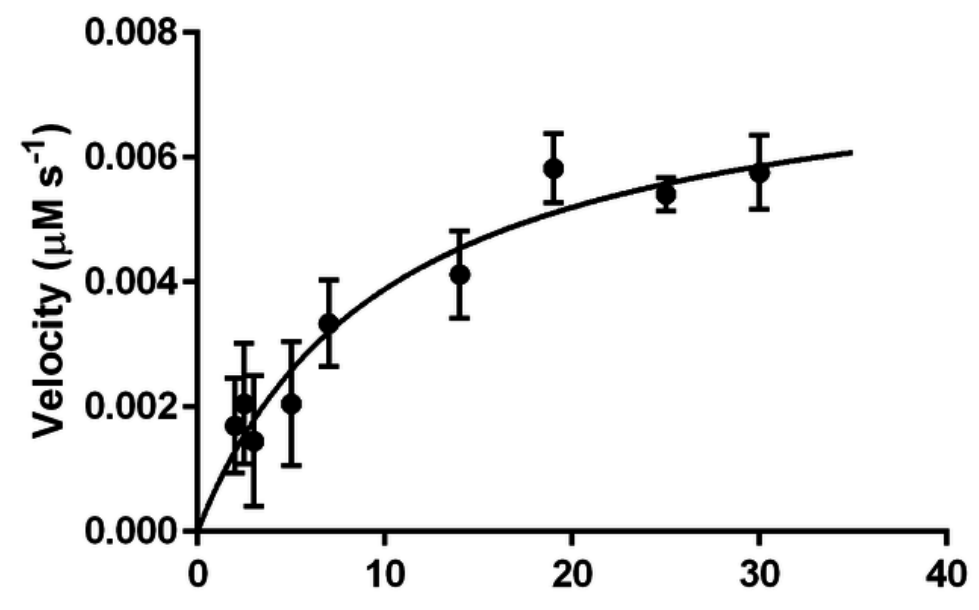

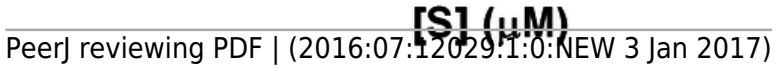




\section{Figure 4}

Headspace solid phase microextraction gas chromatography mass spectrometry (HSSPME-GC-MS) analysis of enzymatic products of recombinant PmSTS and truncated recombinant PmSTS_ $\Delta 24$.

(A) GC-MS chromatogram of sample extracted from in vitro enzymatic reaction containing PmSTS. (B) GC-MS chromatogram of sample extracted from in vitro enzymatic reaction containing PmSTS_ $\Delta 24$. (C-D) GC-MS mass spectra for the compounds of 1 and 2 in Fig. 5A and 5B. According to the NIST11 mass spectral library, the compound 1 and 2 were identified as $\beta$-farnesene and $\beta$-sesquiphellandrene, respectively. 

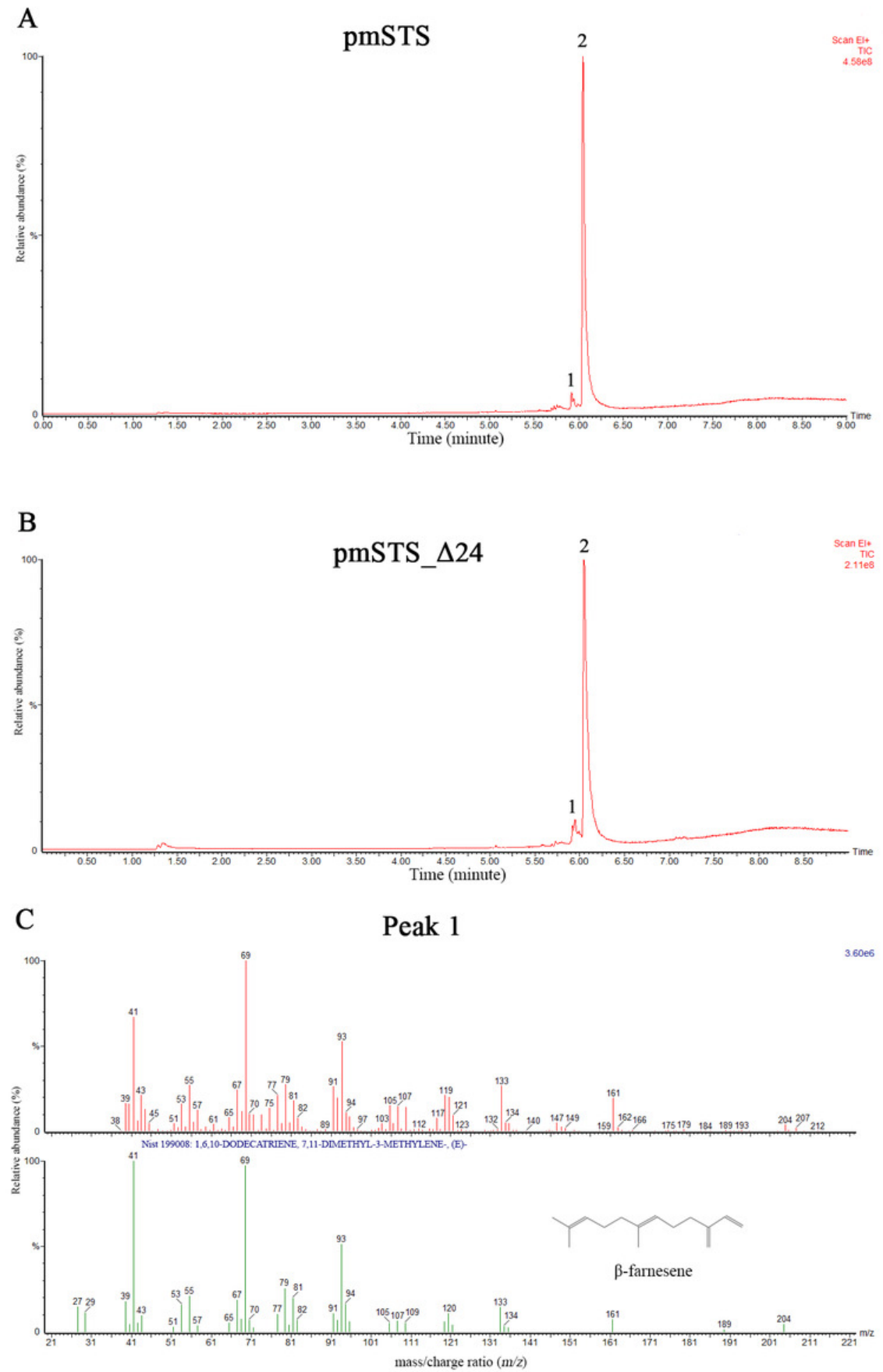

D

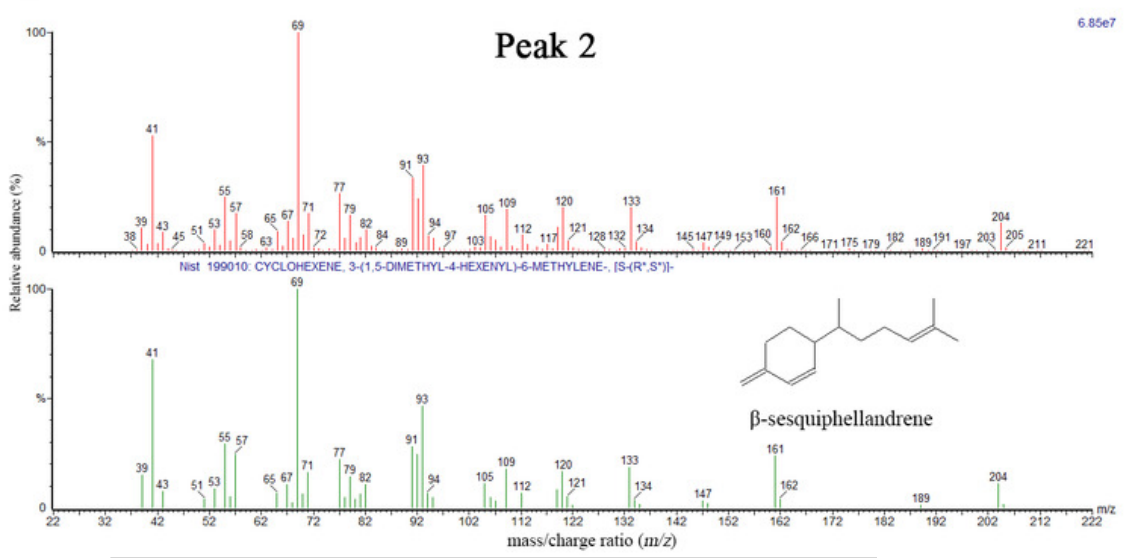

Peer) reviewing PDF | (2016:07:12029:1:0:NEW 3 Jan 2017) 


\section{Figure 5}

Multiple sequence alignment of sesquiterpene synthase metal binding conserved motifs for selected plant sesquiterpene synthases.

The first metal binding motif is highly conserved among the plant sesquiterpene synthases and has a consensus sequence of DDXXD. The second metal binding motif is less conserved and has a consensus sequence of either DDXX(D/E) or (N/D)DXX(T/S/G)XXXE. In PmSTS, the second metal binding motif has the (N/D)DXX(T/S/G)XXXE consensus sequence with alteration, where the conserved $\mathrm{E}$ residue is replaced by V466 as denoted by asterisk. AtGBS (GenBank: CP002687); GhDCS (GenBank: U88318); AgGHS (GenBank: U92267); PaLS (GenBank: AY473625); GaDCS (GenBank: U23206); MdAFS (GenBank: AY182241); HaGCS (GenBank: DQ016668); SbBSS (UniProt: C5YHI2); NtEAS (GenBank: L04680), ZoBBS (GenBank: AB511914); LaBCS (GenBank: DQ263742).

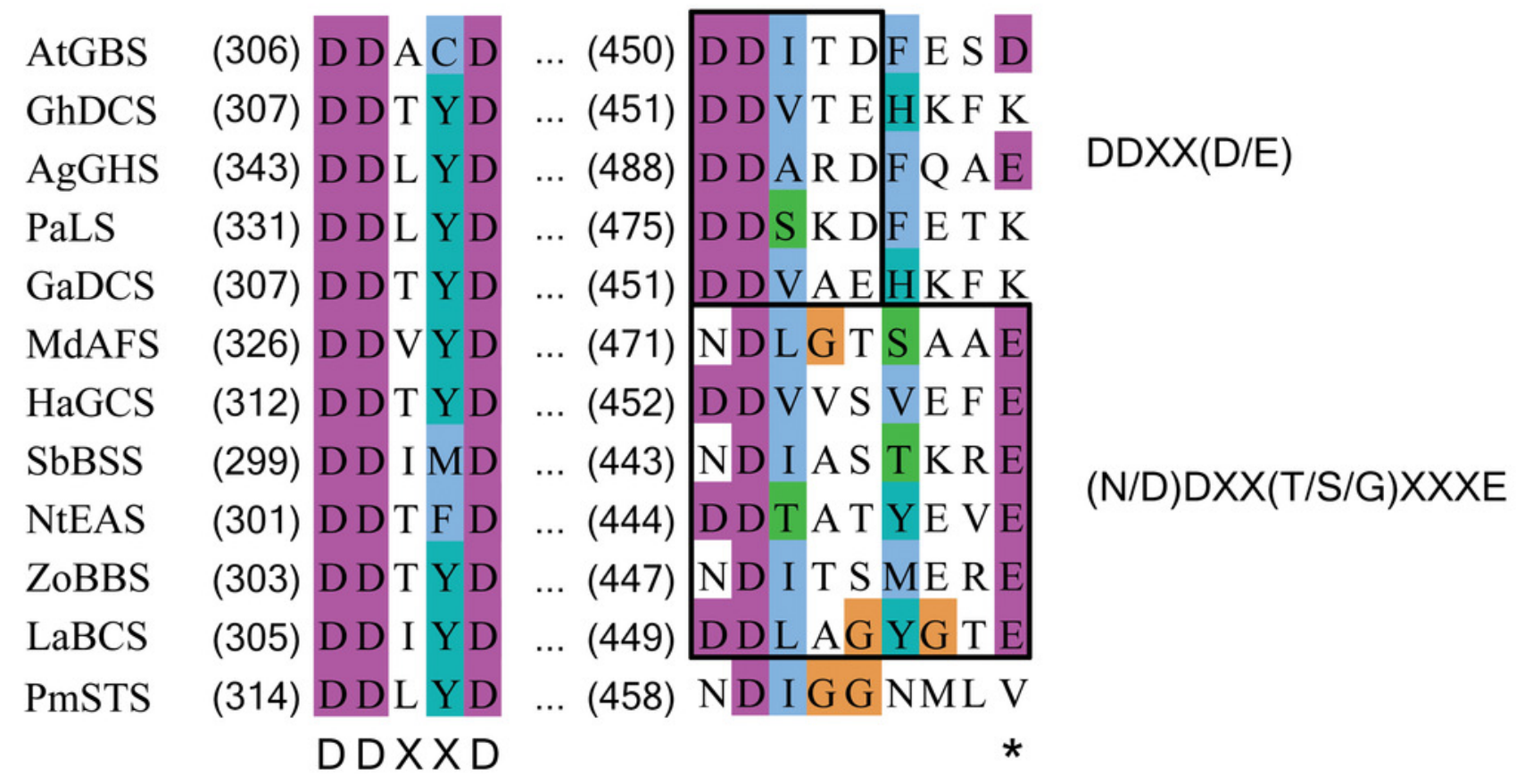




\section{Figure 6}

The homology model of PmSTS shows the structure domain and active site of the enzyme.

(A) The enzyme is made up of $\alpha$-helices architecture structure to contain terpene synthase family N-terminal domain (blue) and C-terminal metal-binding domain (green). The truncated $\mathrm{N}$-terminal (24 amino acid residues) disordered region of PmSTS_ $\Delta 24$ is colored in orange. (B) Superimpose of PmSTS (green) to monoterpene synthase S. officinalis (+)-bornyl diphosphate synthase (SoBDS) (PDB ID:1N20 in purple) and M. spicata 4S-limonene synthase (MsLS) (PDB ID:20NG in yellow), and sesquiterpene N. tabacum 5-epi-aristolochene synthase (NtEAS) (PDB:3M01 in brown), G. arboreum 8-cadinene synthase(GaDCS) (PDB ID: 3G4F in cyan) and A. annua $\alpha$-bisabolol synthase (AaBOS) (PDB ID: 4FJQ in black), reveals the structural conserved RXR and DDXXD motifs, and flexible region (boxed) of J-K and $\mathrm{H} 2-\alpha 1$ loops at the active site. The ligand FPF and trinuclear metal cluster were adopted by superimposed NtEAS structure with PmSTS (C) The active site of PmSTS shows the ligand entrance pocket and the potential enzyme-substrate interactions. The three catalytic important $\mathrm{Mg} 2+$ ions are also shown in magenta sphere. The mutated residues $\mathrm{K} 266 \mathrm{E}$ that found in L. lactis recombinant protein PmSTS ${ }^{\mathrm{K} 266 \mathrm{E}}$ is as stick in helix A.
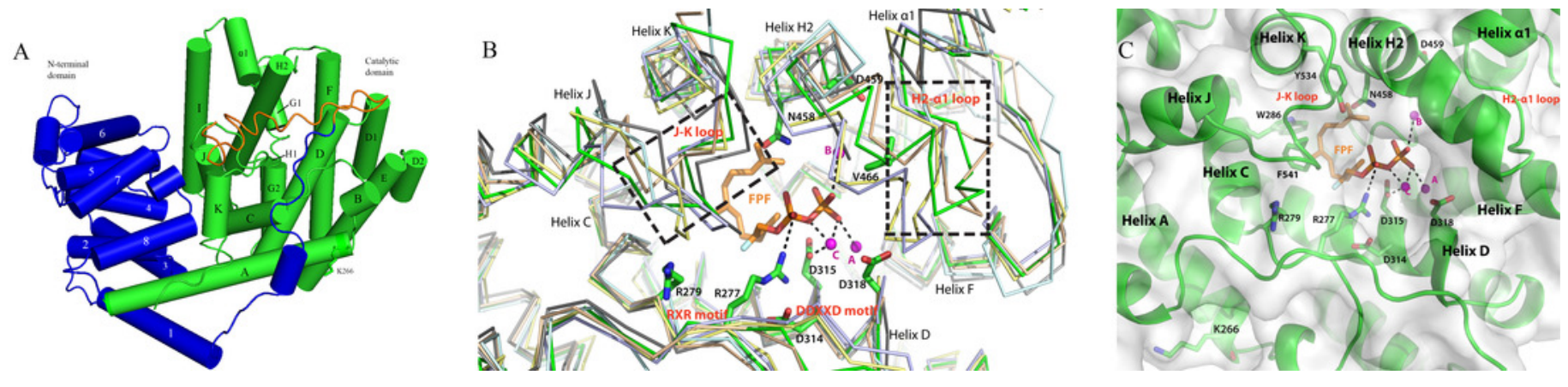


\section{Figure 7}

Proposed formation of the two sesquiterpene products from FPP catalyzed by PmSTS.

The scheme is based on previous study on $\beta$-sesquiphellandrene synthase from Sorghum bicolor (Garms et al., 2012).<smiles>CC(C)=CCCC(C)=CCCOP</smiles>

FPP<smiles>CCCCC</smiles><smiles>CC=C(C)C</smiles>

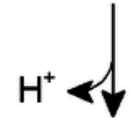<smiles>C=CC(=C)CCC=C(C)CCC=C(C)C</smiles>

$\beta$-farnesene<smiles>CC(C)=CCCC(C)C1CC=C(C)CC1</smiles>

Bisabolyl cation

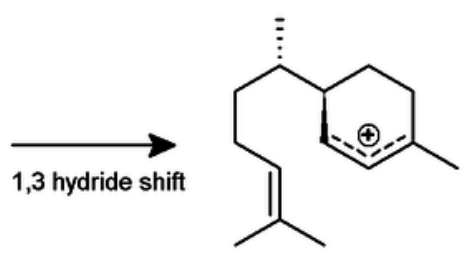

$\mathrm{H}^{+} \longleftarrow$<smiles>C=C1C=CC([C@@H](C)CCC=C(C)C)CC1</smiles>

$\beta$-sesquiphellandrene 


\section{Table $\mathbf{1}$ (on next page)}

Biochemical data of PmSTS compared with other plant sesquiterpene synthases.

1. Patchoulol synthase from Pogostemon cablin (Deguerry et al., 2006).

2. $\alpha$-Bergamotene synthase from Lavandula angustifolia (Landmann et al., 2007).

3. $\beta$-Farnesene synthase from Artemisia annua (Picaud, Brodelius $\&$ Brodelius, 2005).

4. $\beta$-Caryophyllene synthase from Artemisia annua (Cai et al., 2002). 
1

\begin{tabular}{llllll}
\hline & PmSTS_ $\Delta 24$ & 1 & 2 & 3 & 4 \\
\hline $\mathrm{pH}$ & 8.0 & 7.5 & 8.0 & 6.5 & 7.7 \\
Temperature & $30^{\circ} \mathrm{C}$ & $40^{\circ} \mathrm{C}$ & $30^{\circ} \mathrm{C}$ & - & - \\
$K_{\mathrm{m}}(\mu \mathrm{M})$ & 10.2 & 4.45 & 4.7 & 2.1 & 1.8 \\
$k_{\text {cat }}\left(\mathrm{s}^{-1}\right)$ & $7.8 \times 10^{-2}$ & $4.3 \times 10^{-4}$ & $3.3 \times 10^{-2}$ & $9.5 \times 10^{-3}$ & $4.0 \times 10^{-2}$ \\
$k_{\text {cat }} / K_{\mathrm{m}}\left(\mathrm{M}^{-1} \mathrm{~s}^{-1}\right)$ & $7.6 \times 10^{3}$ & 96.6 & $7.0 \times 10^{3}$ & $4.5 \times 10^{3}$ & $2.2 \times 10^{4}$ \\
\hline
\end{tabular}

2 


\section{Table 2 (on next page)}

Structural similarity of between PmSTS and other terpene synthases.

${ }^{1}$ Sequence identity compared with PmSTS.

${ }^{2}$ The rms deviation of $\mathrm{C} \alpha$ atoms and the number of structurally similar residues (in parentheses) compared with PmSTS. 
1

\begin{tabular}{|c|c|c|c|c|c|}
\hline & \multicolumn{3}{|c|}{ Sesquiterpene } & \multicolumn{2}{|c|}{ Monoterpene } \\
\hline & NtEAS & AaBOS & GaDCS & SoBDS & MsLS \\
\hline $\begin{array}{l}\text { PDB } \\
\text { accession } \\
\text { code }\end{array}$ & $3 \mathrm{M} 01$ & 4FJQ & $3 G 4 D$ & $1 \mathrm{~N} 20$ & $2 \mathrm{ONG}$ \\
\hline Organism & $\begin{array}{c}\text { Nicotiana } \\
\text { tabacum }\end{array}$ & $\begin{array}{c}\text { Artemisia } \\
\text { аппиа }\end{array}$ & $\begin{array}{l}\text { Gossypium } \\
\text { arboreum }\end{array}$ & $\begin{array}{c}\text { Salvia } \\
\text { officinalis }\end{array}$ & $\begin{array}{l}\text { Mentha } \\
\text { spicata }\end{array}$ \\
\hline $\begin{array}{l}\text { Terpene } \\
\text { synthase }\end{array}$ & $\begin{array}{l}\text { 5-Epi- } \\
\text { aristolochene }\end{array}$ & $\begin{array}{c}\alpha \text {-Bisabolol } \\
\text { synthase }\end{array}$ & $\begin{array}{c}\delta \text {-Cadinene } \\
\text { synthase }\end{array}$ & $\begin{array}{c}\text { Bornyl } \\
\text { diphosphate } \\
\text { synthase }\end{array}$ & $\begin{array}{c}\text { Limonene } \\
\text { synthase }\end{array}$ \\
\hline $\begin{array}{l}\text { Sequence } \\
\text { identity }^{1}\end{array}$ & $37.6 \%$ & $37.0 \%$ & $40.0 \%$ & $29.5 \%$ & $28.8 \%$ \\
\hline $\mathrm{RMSD}^{2}$ & $1.43(518)$ & $2.26(486)$ & $1.53(502)$ & $1.15(511)$ & $1.26(517)$ \\
\hline
\end{tabular}

2 